\title{
Zic2 abrogates an alternative Wnt signaling pathway to convert axon attraction into repulsion
}

Cruz Morenilla-Palao, Maria Teresa López-Cascales ${ }^{1}$, José P. LópezAtalaya1, Diana Baeza', Luis Calvo-Diaz', Aida Giner de Gracia', Angel Barco $^{1}$ and Eloísa Herrera ${ }^{1 \#^{*}}$

${ }^{1}$ Instituto de Neurociencias. Consejo Superior de Investigaciones CientíficasUniversidad Miguel Hernández (CSIC-UMH). Campus San Juan, Av. Ramón y Cajal s/n, Alicante 03550 (Spain)

*Author for correspondence: e.herrera@umh.es

\# Lead Contact: e.herrera@umh.es

Phone: +34-965-919231 Fax: +34-965-919200

Running tittle: Transcriptional control of an alternative Wnt signaling

Keywords: Wnt signaling; ßcatenin; attraction, repulsion; Wnt5a; Zic2; APC2; LGR5; Eph/ephrin signaling 


\section{ABSTRACT}

Wnt signaling is involved in axon pathfinding during brain wiring but it is unknown how Wnt ligands promote attraction or repulsion. In addition, the participation of the canonical ( $\beta$ catenin-dependent transcription) versus noncanonical (ßcatenin-independent) Wnt pathways in this process remains controversial. Here we show that Wnt5a is expressed at the optic chiasm midline and promotes axon crossing by triggering an alternative Wnt pathway that depends on polarized accumulation of $\beta$ catenin at the axon terminal but does not activate the canonical pathway. Remarkably, this alternative pathway is silenced by the transcription factor Zic2 in the small subset of ipsilaterally projecting neurons. Zic2 directly regulates genes related to Wnt and Eph signaling that lead to global accumulation of ßcatenin but triggers its asymmetric phosphorylation to facilitate the steering of the growth cone. This alternative Wnt pathway found in contralateral axons and its Zic2-mediated abrogation in ipsilateral neurons is likely operating in many other contexts requiring a two-way response to Wnt ligands. 


\section{INTRODUCTION}

To establish neuronal connectivity in the adult brain, neurons located far from their targets must extend an axon that navigates over long distances during embryonic development to reach the correct target tissue. Using simple models such as the axonal binary decision of crossing or not the midline in vertebrates or invertebrates, different families of secreted (Netrin, Slits) and membrane (Eph/ephrins) proteins were initially identified as axon guidance molecules (Chédotal, 2019; Herrera et al., 2019; Stoeckli, 2018). Later, the highly conserved proteins Wnts -originally described as key regulators of body axis patterning, cell fate specification, proliferation, cell migration and carcinogenesis- were found to be also involved in axon guidance and mediate both attractive and repulsive responses in different contexts. While Wnt5 repels ventral nerve axons expressing the Derailed receptor in Drosophila (Fradkin et al., 1995; Yoshikawa et al., 2003), vertebrate postcommissural axons are attracted by Wnts (Lyuksyutova et al., 2003).

Intracellularly, Wnt signaling is a particularly complex pathway that leads to the activation of two main alternative branches. The canonical and the non-canonical pathway with the latter, in turn, being divided into the Planar Cell Polarity (PCP) and calcium pathways. This classification relies on the participation of $\beta$ catenin, an important intracellular signal transducer that links the membrane adhesion protein E-cadherin to the actin cytoskeleton (Jamora and Fuchs, 2002). In the absence of Wnt, ßcatenin is constantly degraded by the destruction complex formed by GSK3, Axin and Apc (Apc2 in the nervous system). In the canonical pathway, the binding of Wnt proteins to their receptors (Frizzled and Lrp5/6) triggers the inactivation or disassembly of 
the destruction complex which reduces ßcatenin phosphorylation and promotes its accumulation and translocation to the nucleus. There, $\beta$ catenin forms a complex with Lef/Tcf factors and induces the transcription of specific genes. In contrast, activation of the non-canonical pathway does not depend on Bcatenin-driven transcription; instead it relies on changes that affect cytoskeletal organization and calcium homeostasis (Rao and Kühl, 2010). The role of classical PCP proteins, in polarizing epithelial tissues made the noncanonical branch the most likely candidate to translate Wnt signals into the polarization of the motile axon growth cone. Consistent with this view, mutant mice for typical PCP receptors such as Celsr3 (Cadherin EGF LAG sevenpass G-type receptor 3, a.k.a Flamingo) or Vangl2 (Van Gogh-like protein 2), exhibit pathfinding defects in the ascending and descending projections of the brainstem, in the longitudinal axis of the spinal cord and in other fiber tracts (Chai et al., 2014; Fenstermaker et al., 2010; Shafer et al., 2011; Tissir et al., 2005). However, more recent studies have shown that manipulation of different components of the canonical pathway, including ßcatenin, alter axon midline behavior in the chick spinal cord (Avilés and Stoeckli, 2016). This, along with studies showing that Wnt5a may act as an activator of the canonical pathway (Mikels and Nusse, 2006), has challenged the idea of PCP as the only Wnt signaling branch involved in guidance. Therefore, the mechanisms by which Wnt proteins mediate axon attraction or repulsion as well as the branch of the Wnt pathway involved in axon guidance remain unclear.

In the developing visual system, retinal ganglion cells (RGCs) projecting ipsilaterally (iRGCs) are located in the peripheral ventro-temporal 
retina and contralaterally projecting ganglion cells (cRGCs) distribute in the remainder retina. The spatial segregation of iRGCs and $\mathrm{cRGCs}$ facilitates their genetic manipulation and the labeling and visualization of individual axons when they are crossing or avoiding the midline. By using this binary system, here we disentangle some of the unknown mechanisms underlying Wnt signaling pathways during axon guidance decisions. We first demonstrate that $\mathrm{cRGC}$ and $\mathrm{iRGC}$ axons transduce Wnt5a signaling differentially. In contralateral neurons, a novel form of Wnt signaling that depends on accumulation of $\beta$ catenin but is non-canonical, is activated to promote midline crossing. In ipsilateral axons, the positive response to Wnt5a is switched off by Zic2, a transcription factor (TF) previously described as the determinant of ipsilateral identity and known to induce the expression of the tyrosine kinase receptor EphB1 (Escalante et al., 2013; García-Frigola et al., 2008; Herrera et al., 2003). Then, we identified the set of genes directly regulated by Zic2 that silence the positive response to Wnt5a. Concomitant with the Zic2-induced blockage of Wnt5a positive signaling, ipsilateral axons undergo EphB1mediated phosphorylation of $\beta$ catenin at the growth cone to trigger asymmetric destabilization of actin filaments and facilitate axon steering. 


\section{RESULTS}

\section{Wnt5a enhances the growth of contralaterally projecting axons}

Wnt signaling is known to play an important role in axonal navigation in different contexts and species, but its function in the guidance of visual axons at the midline has not been explored. To assess the role of Wnt signaling in the navigation of retinal axons, we first analyzed the expression of different members of the Wnt family at the optic chiasm by in situ hybridization. Among the different Wnts expressed at the chiasm region (Figure S1), we found that Wnt5a is expressed at the midline in a spatiotemporal pattern that resembles that of ephrinB2 (Figure 1A), a repulsive guidance molecule expressed by glial cells that induces the turning of iRGCs (Williams et al., 2003). This result points towards Wnt5a being a candidate molecule responsible for mediating axon guidance at the midline.

To investigate whether Wnt5a has an effect on RGC axons, explants from the central retina of E14.5 mouse embryos (i.e. embryos containing contralaterally but not ipsilaterally projecting neurons) were cultured for 12 hours in the presence of Wnt5a. The axons from explants co-cultured with Wnt5a extended significantly longer axons than those not exposed to Wnt5a (Figure 1B-D). These results indicate that RGC axons respond positively to Wnt5a, confirming the participation of Wnt signaling in visual axons pathfinding.

\section{A non-canonical but Bcatenin-dependent branch of the Wnt pathway mediates midline crossing}


Intriguingly, the experiments with retinal explants described above revealed a significant increase in both the levels of $\beta$ catenin and the size of the growth cone after acute exposure of the explant to Wnt5a (Figure 1E-G). To directly assess the participation of $\beta$ catenin in midline crossing, we downregulated Bcatenin in RGCs at the time that the majority of visual axons are crossing the midline. Short hairpin RNA against $\beta$ catenin (Ctnnb shRNA) was injected and electroporated into the retinas of E13.5 mouse embryos and the axonal projection phenotype of targeted neurons at the optic chiasm was analyzed five days later. As a control, retinas were also electroporated with plasmids bearing random shRNAs. In addition, plasmids encoding EGFP were coinjected in both cases to visualize the axons of targeted neurons at the chiasm. While the axons of neurons expressing random shRNAs crossed the midline, those electroporated with Ctnnb shRNA plasmids showed strongly altered axonal trajectories at the midline. While a subpopulation of these axons took the ipsilateral path, most of them stalled at the midline (Figure 2A-B). These results are consistent with previous findings showing midline defects of commissural spinal axons after downregulation of $\beta$ catenin (Avilés and Stoeckli, 2016).

The effects of Wnt5a treatment and the phenotype obtained after knocking down $\beta$ catenin on cRGCs was suggesting that contralateral neurons could be activating the canonical pathway while confronting Wnt5a at the chiasm. To test this hypothesis, we electroporated retinas from E13.5 embryos with a reporter plasmid for canonical Wnt signaling (referred to as Top-RFP) that contains several TCF/LEF binding sites upstream of the coding sequence of the red fluorescence protein (Rabadán et al., 2016). As a positive 
control, we used an $\mathrm{N}$-terminal truncated form of $\beta$ catenin $(\Delta 90 \beta$ cat) that lacks of phosphorylation sites responsible for its degradation and tends to accumulate intracellularly promoting $\beta$ catenin-dependent transcription (Wrobel et al., 2007). Retinas from embryos electroporated with Top-RFP plus $\triangle 90 \beta$ cat expressed high levels of RFP two days later. However, no red signal was detected in retinas electroporated with Top-RFP alone (Figure 2C, D), indicating that although ßcatenin is required for midline crossing, canonical Wnt signaling is not active in RGCs when the axons cross the chiasm.

\section{Zic2 silences the positive response to Wnt5a}

Above we demonstrated that Wnt5a enhances the growth of contralateral axons and triggers the local accumulation of $\beta$ catenin at the tip of the cone. Would ipsilateral axons exhibit a different behavior? Given that the number of iRGCs concentrated at the ventrotemporal retina is too small to prepare explants free of cRGCs, we tested our hypothesis by comparing the axonal response of RGCs electroporated or not with Zic2, the TF that specifies ipsilaterally projecting neurons (Escalante et al., 2013; Herrera et al., 2003). In this model, Zic2-positive RGCs functionally correspond to iRGCs. Retinal explants from embryos electroporated with EGFP alone or with Zic2 plus EGFP were plated on dishes and incubated with Wnt5a for 12 hours (Figure 3A). As expected, the axons of EGFP-electroporated explants (controls) extended significantly longer axons in the presence of Wnt5a than vehicle (Figure 3B, similar to Figure 1C). In contrast, the axons from Zic2expressing explants did not exhibit enhanced growth after Wnt5a treatment (Figure 3A-B), indicating that Zic2 is able to modify the response of 
contralateral axons to Wnt5a. Moreover, the acute exposure of Zic2expressing neurons to Wnt5a resulted in a significant reduction in the size of their growth cones compared to controls (Figure 3C-D), indicating that, although they do not respond by enhancing their growth, Zic2 RGC axons do sense Wnt5a.

\section{Zic2 regulates many genes related to the Wnt signaling in RGC axons}

Our results show that cRGCs and Zic2-iRGCs respond differentially to Wnt5a.

To unveil the mechanisms underlying this change in the axonal response, we analyzed the transcriptome of Zic2-transduced RGCs. Retinas from E13.5 embryos electroporated with Zic2 plus EGFP-encoding plasmids or with EGFP plasmids alone, were isolated and EGFP cells sorted by flow cytometry 36 hours after electroporation. Then, the transcriptomes of EGFP or Zic2/EGFP cells were compared (Figure 4A and S2A). This mRNA-seq screen identified 423 upregulated genes and 192 downregulated genes $\left(\mathrm{P}_{\mathrm{adj}}<\right.$ 0.1) (Figure 4B). As expected, Zic2 was the most upregulated gene (Figure S2B). Genes encoding for the tyrosine receptor EphB1 and the serotonin transporter Sert - previously described as Zic2 targets (García-Frigola et al., 2008; García-Frigola and Herrera, 2010) - were also upregulated (Figure S2C). In addition, Zic2 expression strongly downregulated Sox4, a TF that promotes cRGC differentiation and axonal midline crossing (Kuwajima et al., 2017) (Figure 4B and Figure 5H), as well as Brn3a and Isl2 which have been reported to be expressed in contralateral but not in ipsilaterally projecting neurons (Pak et al., 2004; Quina, 2005) (Figure S2D). Consistent with these results, Gene Ontology (GO) enrichment analysis for differentially expressed 
genes revealed that upregulated genes were associated with biological processes such as Neuron projection and Cell-cell signaling, which are essential processes in axon guidance. Furthermore, the most enriched Cellular Component term was Axon (Figure 4C).

To identify the main signaling pathways affected by Zic2 expression, we conducted a PANTHER pathways analysis that revealed a significant enrichment for genes involved in the Wnt signaling pathway among the upregulated genes (Figure 4D). Gene set enrichment analysis (GSEA) confirmed the significant impact of Zic2 expression on Wnt pathway genes and revealed that Wnt-related genes are also found in the set of genes downregulated by Zic2 (Figure 4E).

To define the gene set directly regulated by Zic2 in axon guidance processes, we performed chromatin immunoprecipitation assays followed by massive sequencing (ChIP-seq) using a specific Zic2 antibody. Since the population of Zic2-expressing RGCs is extremely low (we had to use more than 170 embryos per sample), we additionally prepared chromatin from dorsal spinal cord neurons (dSCNs), which also project ipsilaterally upon Zic2 expression (Escalante et al., 2013) but are much more abundant than iRGCs. The comparison of both profiles showed that although Zic2 peaks are more prominent in dSCNs, likely reflecting the higher number of Zic2 cells in the spinal cord, the occupancy profiles in iRGCs and dSCN are very similar (Figure S3A). This is true with the exception of a few genes, such as EphB1 and EphA4, which are specific for iRGCs and dSCN, respectively (Figure S3B). These latter results are consistent with our previous studies 
demonstrating that Zic2 controls the expression of EphB1 in RGCs and EphA4 in dSCN (Escalante et al., 2013; García-Frigola et al., 2008).

The mapping of Zic2 peaks revealed that Zic2 primarily binds to promoter regions. Although previous analyses in embryonic stem cells reported that Zic2 binds preferentially to enhancer regions (Luo et al., 2015), our results in the chromatin of differentiated neurons indicate that almost $75 \%$ of the peaks map in the proximity of transcription start sites (TSS) $(<1 \mathrm{~kb}$ upstream) (Figure 5A) and only $13.9 \%$ of the peaks locate into putative enhancers (Figure 5B). These results denote fundamental differences either in the binding profile of Zic2 in stem cells and postmitotic neurons.

Intriguingly, the search for motif in Zic2-bound regions using the MEME suite retrieved two consensus binding motifs, which we refer to as motif $A$ and motif $B$ (Figure 5B). Motif $A$ resembles the consensus motif recognized by NRF1 (JASPAR: MA0506.1) and has not been previously associated with Zic2 or any other member of the Zic family, while motif $B$ is similar to a sequence described as a secondary Zic2 binding motif (Ishiguro et al., 2018; Sakai-Kato et al., 2008). Motif A was found in $79 \%$ of the Zic2 peaks, whereas motif B was only found in $21.5 \%$ of the peaks. Zic2 binding to both motifs was detected in $12.1 \%$ of the loci (Figure 5B). Luciferase assays in HEK293 cells transfected with Zic2 in conjunction with plasmids bearing the thymidinekinase basal promoter- $\beta-$ Gal driven by motif $A$ or motif $B$ (see the Material and Methods section), revealed that while Zic2 may interact with both motifs, it shows much higher affinity for motif $A$. As a control, since Zic TFs have been proposed to antagonize Gli TFs and compete for the same binding sites (Mizugishi et al., 2001), we also analyzed Zic2 binding to the Gli binding motif 
and found a similar affinity as for motif B (Figure 5C). Altogether, these results indicate that motif $A$ enables the strongest transactivation by Zic2 recruitment.

Consistent with our mRNA-seq data, GO analysis of Zic2-bound genes in differentiated neurons revealed a significant enrichment for the Wnt signaling pathway (Figure S3C). Moreover, Wnt signaling was also the most enriched pathway among the genes that were both detected as Zic2-bound in the ChIP-seq screen and differentially expressed in the mRNA-seq screen (Figure 5D-G). The overlapping gene set (94 genes; Table S1) includes a $37 \%$ of downregulated genes and $63 \%$ of upregulated genes and Wnt-related Zic2 targets are found in both groups. Key components of the pathway, such as Apc2 or Sox4, are downregulated (Figure $5 \mathrm{H}$ ), while others, such as Fzd1, Fzd8, Lgr5, En2 or Diversin/Ankrd6, are upregulated (Figure 5I) in Zic2expressing retinal cells, suggesting that Zic2 may act as an activator or a repressor depending on the genomic context, likely forming complexes with other TFs. Notably, Zic2 peaks were found at the promoter (25\%) or intronic putative enhancers (37\%) of these bona fide target genes, and $80 \%$ of them included motif $A$ in the regulatory sequences (Figure 5E, F and Figure S3). Remarkably, NRF1, the TF that also recognizes the motif A found in Zic2 peaks, has been proposed to interfere with the Wnt canonical pathway in Drosophila (Xin et al., 2011). Interestingly, other Wnt-related genes such as Ctnnb1 (ßcatenin), Ryk, Rhoa, Gsk3b, Pias4, Rock1, Dvl1, Dv2 and Axin1, which showed strong Zic2 binding to their promoters, did not change their expression upon Zic2 induction (Figure S3). 
Overall, these genome-wide analyses show that Zic2 regulates very similar genetic programs in different types of ipsilaterally projecting neurons and underscore a strong link between Zic2 and the Wnt pathway.

\section{The gene network triggered by Zic2 promotes accumulation of $\beta$ catenin}

To further define the molecular mechanism underlying the control of Zic2 in the Wnt pathway, we sought to validate our genomic screens by performing in situ hybridization (ISH) and immunostaining in retinal sections for some of the candidate genes retrieved in both screens (RNA-seq + ChIP-seq). Thus, ISH for Fzd8 mRNA demonstrated a restricted expression in the ventrotemporal retina coinciding with the position of Zic2-expressing iRGCs (Figure 6A and data not shown), which is consistent with its upregulation in Zic2electroporated neurons. By immunostaining, we also confirmed the downregulation of $A p c 2$ in the growth cone of Zic2-expressing neurons (Figure 6B), consistent with previous studies suggesting that Apc regulates axon behavior and is required for midline crossing (Arbeille and Bashaw, 2018; Purro et al., 2008). Intriguingly, also consistent with the known role of Apc2 as an integrant of the $\beta$ catenin degradation complex, we also observed a significant and homogeneous accumulation of ßcatenin in the same terminals (Figure 6B). Lgr5, a G-protein-coupled-responding receptor proposed to trigger the canonical Wnt signaling pathway upon ligand binding (de Lau et al., 2011), was also upregulated by Zic2 (Figure 5J). These results indicate that although Ctnnb (the gene encoding ßcatenin) transcription is not directly affected by Zic2 (Figure S3B), the presence of this TF indirectly regulates the levels of $\beta$ catenin and produces a uniform accumulation of this 
protein in the neuron. This $\beta$ catenin accumulation did not activate however the canonical pathway as electroporation of Top-RFP plasmids in Zic2 neurons did not result in RFP expression. In fact, retinas electroporated with Zic2, Top-RFP and $\Delta 90$ - $\beta$ cat plasmids showed a significant reduction in RFP expression compared to the control (Figure 6D, E), indicating that instead of inducing canonical Wnt signaling, Zic2 is able to inhibit this pathway. On the contrary, a significant inhibition of $\beta$ catenin-dependent transcription was observed (Figure 6D, E), consistent with our observation that En2, a TF involved in the nuclear translocation of ßcatenin (Lin et al., 2018), is also downregulated upon Zic2 expression (Figure S2).

Downregulation of $\beta$ catenin provokes axon midline stalling and Zic2 induces uniform accumulation of $\beta$ catenin. These results inspired the idea that Wnt5a-induced polarized accumulation of $\beta$ catenin in the axon terminal is essential for crossing and spoiling this polarization would disturb crossing. To address this hypothesis, we analyzed E16.5 embryos electroporated at E13.5 with plasmids encoding either wildtype (wt) Bcatenin or a variant form of this protein that is resistant to Apc2-mediated degradation and also lacks the transactivation domain ( $\Delta \mathrm{CT}-\beta \mathrm{c}$ at). The chiasm of embryos electroporated with wt ßcatenin-plasmids were undistinguishable from the controls electroporated with EGFP encoding plasmids alone. However, forced unpolarized accumulation of $\beta$ catenin achieved by the expression of this nondegradable truncated protein lead to an almost random projection phenotype with axons choosing either the ipsi or contralateral route (Figure 6F-G).

\section{Asymmetric phosphorylation of $\beta$ catenin facilitates axon steering.}


Previous reports have shown that the tyrosine kinase receptor EphB1, a direct target for Zic2, is necessary for the ipsilateral projection to form. However, electroporation of EphB1 in RGCs was known to induce midline avoidance with much less efficiency than electroporation of Zic2 (García-Frigola et al., 2008; Petros et al., 2009). This, already pointed to the existence of mechanisms, other than EphB/ephrinB signaling, involved in axon midline avoidance. However, such mechanisms had remained unknown until now. Together with our results showing that disrupting polarized accumulation of Bcatenin produces a random projection at the midline, these observations suggested that inducing EphB1 expression in cRGCs at the same time that abolishing the capacity of the axon to respond to Wnt5a should increase the number of axons steering at the midline compared to when EphB1 is expressed alone. To test this idea, we electroporated EphB1- and Ctnnb shRNA-encoding plasmids at E13.5 and analyzed the optic chiasms of electroporated embryos two days later. As expected, blocking the capacity of the axons to respond to Wnt5a by reducing the levels of $\beta$ catenin and concomitantly inducing the expression of EphB1, almost doubled the number of axons changing their laterality compared to when only EphB1-plasmids were electroporated (Figure 7A-C).

These results suggested that ipsilateral neurons need to silence the positive response to $\mathrm{Wnt5a}$ to prevent crossing at the same time that inducing asymmetric cytoskeleton destabilization upon activation of EphB1 by ephrinB2 binding to promote steering. Although there is no evidence showing interactions between $\beta$ catenin and Eph receptors, crosstalk between these membrane proteins and Wnt signaling has been suggested in oncogenic 
contexts (Clevers and Batlle, 2006). Bcatenin links membrane integrated cadherins to actin filaments and promotes cytoskeleton stabilization (Kim and Lee, 2001; Piedra et al., 2001; Roura et al., 1999). Both the levels and subcellular localization of $\beta$ catenin are tightly regulated by phosphorylation (Valenta et al., 2012). Taking all these observations into account, we considered the idea that EphB1 phosphorylates ßcatenin to facilitate asymmetric cytoskeleton disassembly in ipsilaterally projecting neurons.

To tackle this hypothesis, we activated the EphB1 receptor by overexpression (Wimmer-Kleikamp et al., 2004) in HEK293 cells and performed immunoprecipitation (IP) assays using antibodies against $\beta$ catenin and phospho-tyrosine. We also transfected the cells with an EGFP-encoding plasmid or with plasmids containing a truncated version of the EphB1 receptor lacking the kinase domain (EphB1- $\Delta \mathrm{CT}$ ) as a control. We detected a large enrichment of Bcatenin in the pool of immunoprecipitated tyrosinephosphorylated proteins obtained from EphB1-transfected cells compared to GFP- and EphB1- $\triangle$ CT-transfected cells (Figure 7C). Consistently, we detected tyrosine-phosphorylation at a band that corresponds to the molecular weight of $\beta$ catenin in IPs using an antibody against $\beta$ catenin. This phosphoTyr-band was stronger in extracts from EphB1-transfected cells than from GFP- and EphB1- $\Delta$ CT-transfected cells (Figure 7D). Both experiments indicate that ßcatenin is phosphorylated at a tyrosine residue/s by EphB1. Furthermore, mass spectrophotometry analysis of the immunoprecipitated product revealed that $\beta$ catenin phosphorylation occurs at the tyrosine residue 654 (Y654) upon EphB1 activation (Figure 7E). 
Y654- $\beta$ catenin has a reduced affinity for the cadherins integrated in the cell membrane (Kim and Lee, 2001) and consistent with this, we detected Y654- $\beta$ catenin by immunofluorescence at the cytoplasm rather than in the plasma membrane and totally excluded from the nuclei of cells transfected with EphB1 plasmids. In addition, Y654-ßcatenin cells exhibited smaller areas and adopted rounded shapes compared to control cells that occupied an extended area and exhibited more polygonal silhouettes (Figure 7F-H). These results revealed an increase in cell detachment induced by EphB1mediated phosphorylation of $\beta$ catenin and support a model in which, EphB1 asymmetrically phosphorylates $\beta$ catenin in the growth cone upon activation by ephrinB2 at the midline to induce polarized cytoskeleton destabilization that allow axon steering.

\section{DISCUSSION}

\section{An alternative $\beta$ catenin dependent but not-canonical Wnt pathway acts}

\section{in axon guidance}

The participation and the mode of action of the Wnt signaling pathways in axon guidance has been a controversial issue for years (Avilés and Stoeckli, 2016; Bovolenta et al., 2006; Domanitskaya et al., 2010; Lyuksyutova et al., 2003; Wolf et al., 2008). Our results reconcile all the previous observations about the participation of the canonical versus the non-canonical Wnt pathway in axon navigation, by revealing a third via that regulates crossing and it is independent on $\beta$ catenin-mediated transcription but relays on its local accumulation. This form of signal transduction is remarkably different to the canonical pathway because the changes in $\beta$ catenin stability are restricted to 
the axon terminal compartment and never reaches the cell nucleus nor trigger transcription. However, because it involves $\beta$ catenin dynamics is not the classical PCP pathway either.

In contralaterally projecting axons, Wnt5a binding induces polarized accumulation of $\beta$ catenin, which in turn leads to cytoskeleton stabilization at the tip of the growth cone and promotes midline crossing. In contrast, the presence of the transcription factor Zic2 in ipsilaterally projecting neurons, induces a gene program that silences this positive response to Wnt5a and triggers instead EphB1-dependent phosphorylation of $\beta$ catenin that allows cytoskeleton destabilization (Figure 7I).

Interestingly, our genomic analysis also revealed that from those Wntrelated genes showing Zic2 occupancy, only a subset is differentially expressed after Zic2 induction (e.g., Fz1, Fz8, Lrg5, Apc2, Sox4 or Diversin/Annkr6). We did not find Zic2-peaks in genes specifically associated with the PCP pathway, such as VanGogh/Strabismus (Vang/Stbm), Flamingo (Fmi), Prickle (Pk), JNK, c-jun, or AP-1 except for Diversin/Ankrd6, a protein that recruits $\mathrm{CKI}$-epsilon to the $\beta$ catenin degradation complex and has been described as a molecular switch between the canonical and the non-canonical pathway (Jones et al., 2014; Schwarz-Romond et al., 2002).

Together, these findings clarify many aspects of the long-standing debate about Wnt signaling pathways in axon pathfinding. First, this work shows that Wnt5a elicits attractive or repulsive responses in the same type of neurons depending on a particular transcriptional program that controls the expression of a set of receptors and specific intracellular proteins. Moreover, they reveal that axon repulsion cannot be achieved only through the action of 
repulsive receptors since ipsilateral axons need to silence attractive mechanisms for effective steering. Finally, they also clarify that Wnts do not activate the canonical or PCP pathways in axon guidance processes but complex mechanisms based on $\beta$ catenin dynamics at the growth cone.

\section{Zic2-silencing of the alternative Wnt pathway likely operates in other contexts}

Our study does not only reveal a new branch of the Wnt signaling pathway, it also identifies the TF responsible for the two-way switch in signal transduction. We propose that a similar switch in the response to Wnt ligands may operate in other tissues and contexts where Wnt signaling and Zic2 coexist beyond axon guidance. For instance, Zic proteins are expressed in several populations of migrating neuroblasts in the forebrain, hindbrain and neural tube as well as in neural stem cells in the adult individual (Herrera, 2018; Inoue et al., 2007; Merkle et al., 2014; Murillo et al., 2015; TeSlaa et al., 2013a; Tiveron et al., 2017). In all these contexts, cells expressing Zic TFs are in contact with Wnt proteins (Herrera, 2018) and delaminate from a neuroepithelium undergoing shape rearrangements before migrating through stereotyped paths. Ipsilaterally projecting neurons, or at least a significant number of them, also originate from an epithelium-like area known as the ciliary marginal zone (Fernández-Nogales et al., 2019; Marcucci et al., 2016) and the cell bodies of these cells are exposed to Wnt ligands secreted from this peripheral retinal area (Denayer et al., 2008; Meyers et al., 2012). In these cells, Zic2 likely plays a two-fold function regarding Wnt signaling. In addition to regulate axon guidance as we show here, it would block the 
canonical pathway to prevent proliferation, guaranteeing that the recently differentiated neurons do not reenter the cell cycle. Consistent with this idea, it has been shown that activation of Wnt signaling alters the number of ipsilaterally projecting neurons potentially by keeping them in the cell cycle (Iwai-Takekoshi et al., 2018). Furthermore, experiments in zebrafish and human cell lines suggest that Zic2 blocks the canonical Wnt signaling pathway (Pourebrahim et al., 2011), a result that we have also confirmed here (Figure 3E, F) and that could occur in particular contexts concomitantly with its role in regulating the alternative Wnt pathway.

Zic2 mutations in mice and humans cause holoprosencephaly type IV, anencephaly and spina bifida (Brown et al., 1998; Nagai et al., 2000) likely as a consequence of defects in early developmental stages such as gastrulation and/or neurulation (Houtmeyers et al., 2016; TeSlaa et al., 2013b). In addition, accumulating evidence shows that this TF is upregulated in many different types of cancer (for a recent review see Houtmeyers et al., 2018). However, the molecular mechanisms underlying these Zic2-associated anomalies have remained largely elusive. Recent reports have also shown novel roles for Wnt signaling in the injured CNS (Garcia et al., 2018). Wnt and Eph/ephrin pathways both play key functions in all these processes. While further experiments should revisit the role of Zic2 in early development and oncogenic scenarios, our results support the idea that Zic2 may regulate the crosstalk between the Eph and Wnt pathways in many different contexts. 


\section{ACKNOWLEDGEMENTS}

We thank Y. Coca, and M. Herrera for technical assistance. We also thank P.

Bovolenta and C. Mason for discussion and comments on the manuscript.

The laboratory of EH is funded with the following grants: (BFU2016-77605

from the National Grant Research Program, PROMETEO Program (2016/026)

from Generalitat Valenciana, (PCIN2015-192-C02-02 from ERA-Net Program)

and (ERC-282329 from the European Research Council). MLC is the recipient

of a FPI fellowship from the National Grant Research Program. J. L-A

research is supported by grants RYC-2015-18056 and RTI2018-102260-B-

100 from MICINN co-financed by ERDF. A.B. research is supported by grants

SAF2017-87928-R from MICINN co-financed by ERDF,

PROMETEO/2016/026 from the Generalitat Valenciana. We also

acknowledge the financial support received from the "Severo Ochoa" Program

for Centers of Excellence in R\&D (SEV-2013-0317). 


\section{AUTHOR CONTRIBUTIONS}

C M-P designed, performed and analyzed most of the experiments. MT L-C and JP L-A have performed the computational analysis of RNA-seq and ChIPseq data. DB performed in situ hybridizations and took care of the mice colonies. L C-D and A G-G performed some immunostainings. EH wrote the original draft and designed, conceived and supervised the study. AB revised subsequent versions of the manuscript and helped with experimental design and revisited critically the manuscript for important intellectual content. 


\section{REFERENCES}

Anders, S., Pyl, P.T., and Huber, W. (2015). HTSeq--a Python framework to work with high-throughput sequencing data. Bioinformatics 31, 166-169.

Arbeille, E., and Bashaw, G.J. (2018). Brain Tumor promotes axon growth across the midline through interactions with the microtubule stabilizing protein Apc2. PLoS Genet. 14, e1007314.

Avilés, E.C., and Stoeckli, E.T. (2016). Canonical wnt signaling is required for commissural axon guidance. Dev. Neurobiol. 76, 190-208.

Bailey, T.L., Boden, M., Buske, F.A., Frith, M., Grant, C.E., Clementi, L., Ren, J., Li, W.W., and Noble, W.S. (2009). MEME SUITE: tools for motif discovery and searching. Nucleic Acids Res. 37, W202-W208.

Bovolenta, P., Rodriguez, J., and Esteve, P. (2006). Frizzled/RYK mediated signalling in axon guidance. Development 133, 4399-4408.

Brown, S.A., Warburton, D., Brown, L.Y., Yu, C., Roeder, E.R., Stengel-

Rutkowski, S., Hennekam, R.C.M., and Muenke, M. (1998).

Holoprosencephaly due to mutations in ZIC2, a homologue of Drosophila oddpaired. Nat. Genet. 20, 180-183.

Chai, G., Zhou, L., Manto, M., Helmbacher, F., Clotman, F., Goffinet, A.M., and Tissir, F. (2014). Celsr3 is required in motor neurons to steer their axons in the hindlimb. Nat. Neurosci. 17, 1171-1179.

Chédotal, A. (2019). Roles of axon guidance molecules in neuronal wiring in the developing spinal cord. Nat. Rev. Neurosci.

Clevers, H., and Batlle, E. (2006). EphB/EphrinB Receptors and Wnt

Signaling in Colorectal Cancer: Figure 1. Cancer Res. 66, 2-5.

Denayer, T., Locker, M., Borday, C., Deroo, T., Janssens, S., Hecht, A., van 
Roy, F., Perron, M., and Vleminckx, K. (2008). Canonical Wnt Signaling

Controls Proliferation of Retinal Stem/Progenitor Cells in Postembryonic

Xenopus Eyes. Stem Cells 26, 2063-2074.

Dobin, A., Davis, C.A., Schlesinger, F., Drenkow, J., Zaleski, C., Jha, S.,

Batut, P., Chaisson, M., and Gingeras, T.R. (2013). STAR: ultrafast universal

RNA-seq aligner. Bioinformatics 29, 15-21.

Domanitskaya, E., Wacker, A., Mauti, O., Baeriswyl, T., Esteve, P., Bovolenta,

P., and Stoeckli, E.T. (2010). Sonic Hedgehog Guides Post-Crossing

Commissural Axons Both Directly and Indirectly by Regulating Wnt Activity. J.

Neurosci. 30, 11167-11176.

Escalante, A., Murillo, B., Morenilla-Palao, C., Klar, A., and Herrera, E.

(2013). Zic2-dependent axon midline avoidance controls the formation of major ipsilateral tracts in the CNS. Neuron 80.

Fenstermaker, A.G., Prasad, A.A., Bechara, A., Adolfs, Y., Tissir, F., Goffinet, A., Zou, Y., and Pasterkamp, R.J. (2010). Wnt/planar cell polarity signaling controls the anterior-posterior organization of monoaminergic axons in the brainstem. J. Neurosci. 30, 16053-16064.

Fernández-Nogales, M., Murcia-Belmonte, V., Chen, H.Y., and Herrera, E. (2019). The peripheral eye: A neurogenic area with potential to treat retinal pathologies? Prog. Retin. Eye Res. 68, 110-123.

Fradkin, L.G., Noordermeer, J.N., and Nusse, R. (1995). The Drosophila Wnt Protein DWnt-3 Is a Secreted Glycoprotein Localized on the Axon Tracts of the Embryonic CNS. Dev. Biol. 168, 202-213.

García-Frigola, C., Carreres, M.I., Vegar, C., Mason, C., and Herrera, E. (2008). Zic2 promotes axonal divergence at the optic chiasm midline by 
EphB1-dependent and -independent mechanisms. Development 135.

Garcia, A., Udeh, A., Kalahasty, K., and Hackam, A. (2018). A growing field:

The regulation of axonal regeneration by Wnt signaling. Neural Regen. Res.

$13,43$.

GarcíFrigola, C., and Herrera, E. (2010). Zic2 regulates the expression of Sert to modulate eye-specific refinement at the visual targets. EMBO J. 29.

Heinz, S., Benner, C., Spann, N., Bertolino, E., Lin, Y.C., Laslo, P., Cheng, J.X., Murre, C., Singh, H., and Glass, C.K. (2010). Simple Combinations of Lineage-Determining Transcription Factors Prime cis-Regulatory Elements Required for Macrophage and B Cell Identities. Mol. Cell 38, 576-589. Herrera, E. (2018). Rodent Zic genes in neural network wiring. Herrera, E., Brown, L., Aruga, J., Rachel, R.A., Dolen, G., Mikoshiba, K., Brown, S., and Mason, C.A. (2003). Zic2 patterns binocular vision by specifying the uncrossed retinal projection. Cell 114.

Herrera, E., Erskine, L., and Morenilla-Palao, C. (2019). Guidance of retinal axons in mammals. Semin. Cell Dev. Biol. 85, 48-59.

Houtmeyers, R., Tchouate Gainkam, O., Glanville-Jones, H.A., Van den Bosch, B., Chappell, A., Barratt, K.S., Souopgui, J., Tejpar, S., and Arkell, R.M. (2016). Zic2 mutation causes holoprosencephaly via disruption of NODAL signalling. Hum. Mol. Genet. 25, 3946-3959.

Houtmeyers, R., Souopgui, J., and Tejpar, S. (2018). Deregulation of ZIC Family Members in Oncogenesis. (Springer, Singapore), pp. 329-338. Huber, W., Carey, V.J., Gentleman, R., Anders, S., Carlson, M., Carvalho, B.S., Bravo, H.C., Davis, S., Gatto, L., Girke, T., et al. (2015). Orchestrating high-throughput genomic analysis with Bioconductor. Nat. Methods 12, 115- 
121.

Inoue, T., Ota, M., Mikoshiba, K., and Aruga, J. (2007). Zic2 and Zic3

synergistically control neurulation and segmentation of paraxial mesoderm in mouse embryo. Dev. Biol. 306, 669-684.

Ishiguro, A., Hatayama, M., Otsuka, M.I., and Aruga, J. (2018). Link between the causative genes of holoprosencephaly: Zic2 directly regulates Tgif1 expression. Sci. Rep. 8, 2140.

Iwai-Takekoshi, L., Balasubramanian, R., Sitko, A., Khan, R., Weinreb, S., Robinson, K., and Mason, C. (2018). Activation of Wnt signaling reduces ipsilaterally projecting retinal ganglion cells in pigmented retina. Development 145, dev163212.

Jamora, C., and Fuchs, E. (2002). Intercellular adhesion, signalling and the cytoskeleton. Nat. Cell Biol. 4, E101-E108.

Jones, C., Qian, D., Kim, S.M., Li, S., Ren, D., Knapp, L., Sprinzak, D., Avraham, K.B., Matsuzaki, F., Chi, F., et al. (2014). Ankrd6 is a mammalian functional homolog of Drosophila planar cell polarity gene diego and regulates coordinated cellular orientation in the mouse inner ear. Dev. Biol. 395, 62-72.

Kim, K., and Lee, K. (2001). TYROSINE PHOSPHORYLATION

TRANSLOCATES $\beta$-CATENIN FROM CELL-CELL INTERFACE TO THE CYTOPLASM, BUT DOES NOT SIGNIFICANTLY ENHANCE THE LEF-1DEPENDENT TRANSACTIVATING FUNCTION. Cell Biol. Int. 25, 421-427.

Kuwajima, T., Soares, C.A., Sitko, A.A., Lefebvre, V., and Mason, C. (2017). SoxC Transcription Factors Promote Contralateral Retinal Ganglion Cell Differentiation and Axon Guidance in the Mouse Visual System. Neuron 93, 1110-1125.e5. 
de Lau, W., Barker, N., Low, T.Y., Koo, B.-K., Li, V.S.W., Teunissen, H., Kujala, P., Haegebarth, A., Peters, P.J., van de Wetering, M., et al. (2011). Lgr5 homologues associate with Wnt receptors and mediate R-spondin signalling. Nature 476, 293-297.

Li, H., and Durbin, R. (2010). Fast and accurate long-read alignment with Burrows-Wheeler transform. Bioinformatics 26, 589-595.

Li, H., Handsaker, B., Wysoker, A., Fennell, T., Ruan, J., Homer, N., Marth, G., Abecasis, G., and Durbin, R. (2009a). The Sequence Alignment/Map format and SAMtools. Bioinformatics 25, 2078-2079.

Li, H., Handsaker, B., Wysoker, A., Fennell, T., Ruan, J., Homer, N., Marth, G., Abecasis, G., and Durbin, R. (2009b). The Sequence Alignment/Map format and SAMtools. Bioinformatics 25, 2078-2079.

Liao, Y., Smyth, G.K., and Shi, W. (2014). featureCounts: an efficient general purpose program for assigning sequence reads to genomic features.

Bioinformatics 30, 923-930.

Lin, X., Liu, X., and Gong, C. (2018). Expression of engrailed homeobox 2 regulates the proliferation, migration and invasion of non-small cell lung cancer cells. Oncol. Lett. 16, 536-542.

Love, M.I., Huber, W., and Anders, S. (2014). Moderated estimation of fold change and dispersion for RNA-seq data with DESeq2. Genome Biol. 15, 550.

Luo, Z., Gao, X., Lin, C., Smith, E.R., Marshall, S.A., Swanson, S.K., Florens, L., Washburn, M.P., and Shilatifard, A. (2015). Zic2 Is an Enhancer-Binding Factor Required for Embryonic Stem Cell Specification. Mol. Cell 57, 685694. 
Lyuksyutova, A.I., Lu, C.-C., Milanesio, N., King, L.A., Guo, N., Wang, Y., Nathans, J., Tessier-Lavigne, M., and Zou, Y. (2003). Anterior-posterior guidance of commissural axons by Wnt-frizzled signaling. Science 302, 19841988.

Marcucci, F., Murcia-Belmonte, V., Wang, Q., Coca, Y., Ferreiro-Galve, S., Kuwajima, T., Khalid, S., Ross, M.E., Mason, C., and Herrera, E. (2016). The Ciliary Margin Zone of the Mammalian Retina Generates Retinal Ganglion Cells. Cell Rep. 17.

Merkle, F.T., Fuentealba, L.C., Sanders, T.A., Magno, L., Kessaris, N., and Alvarez-Buylla, A. (2014). Adult neural stem cells in distinct microdomains generate previously unknown interneuron types. Nat. Neurosci. 17, 207-214. Meyers, J.R., Hu, L., Moses, A., Kaboli, K., Papandrea, A., and Raymond, P.A. (2012). $\beta$-catenin/Wnt signaling controls progenitor fate in the developing and regenerating zebrafish retina. Neural Dev. 7, 30.

Mi, H., Muruganujan, A., Huang, X., Ebert, D., Mills, C., Guo, X., and Thomas, P.D. (2019). Protocol Update for large-scale genome and gene function analysis with the PANTHER classification system (v.14.0). Nat. Protoc. 14, 703-721.

Mikels, A.J., and Nusse, R. (2006). Purified Wnt5a Protein Activates or Inhibits $\beta$-Catenin-TCF Signaling Depending on Receptor Context. PLoS Biol. 4, e115.

Mizugishi, K., Aruga, J., Nakata, K., and Mikoshiba, K. (2001). Molecular properties of Zic proteins as transcriptional regulators and their relationship to GLI proteins. J. Biol. Chem. 276, 2180-2188.

Murillo, B., Ruiz-Reig, N., Herrera, M., Fairén, A., and Herrera, E. (2015). Zic2 
controls the migration of specific neuronal populations in the developing forebrain. J. Neurosci. 35.

Nagai, T., Aruga, J., Minowa, O., Sugimoto, T., Ohno, Y., Noda, T., and

Mikoshiba, K. (2000). Zic2 regulates the kinetics of neurulation. Proc. Natl.

Acad. Sci. U. S. A. 97, 1618-1623.

Pak, W., Hindges, R., Lim, Y.-S., Pfaff, S.L., and O'Leary, D.D.M. (2004).

Magnitude of Binocular Vision Controlled by Islet-2 Repression of a Genetic

Program that Specifies Laterality of Retinal Axon Pathfinding. Cell 119, 567-

578.

Petros, T.J., Shrestha, B.R., and Mason, C. (2009). Specificity and Sufficiency of EphB1 in Driving the Ipsilateral Retinal Projection. J. Neurosci. 29, 34633474.

Piedra, J., Martinez, D., Castano, J., Miravet, S., Dunach, M., and de Herreros, A.G. (2001). Regulation of beta-catenin structure and activity by tyrosine phosphorylation. J. Biol. Chem. 276, 20436-20443.

Pourebrahim, R., Houtmeyers, R., Ghogomu, S., Janssens, S., Thelie, A., Tran, H.T., Langenberg, T., Vleminckx, K., Bellefroid, E., Cassiman, J.-J., et al. (2011). Transcription Factor Zic2 Inhibits Wnt/ß-Catenin Protein Signaling. J. Biol. Chem. 286, 37732-37740.

Purro, S.A., Ciani, L., Hoyos-Flight, M., Stamatakou, E., Siomou, E., and Salinas, P.C. (2008). Wnt regulates axon behavior through changes in microtubule growth directionality: a new role for adenomatous polyposis coli. J. Neurosci. 28, 8644-8654.

Quina, L.A. (2005). Brn3a-Expressing Retinal Ganglion Cells Project Specifically to Thalamocortical and Collicular Visual Pathways. J. Neurosci. 
$25,11595-11604$.

Rabadán, M.A., Herrera, A., Fanlo, L., Usieto, S., Carmona-Fontaine, C., Barriga, E.H., Mayor, R., Pons, S., and Martí, E. (2016). Delamination of neural crest cells requires transient and reversible Wnt inhibition mediated by Dact1/2. Development 143, 2194-2205.

Rao, T.P., and Kühl, M. (2010). An updated overview on Wnt signaling pathways: a prelude for more. Circ. Res. 106, 1798-1806.

Roura, S., Miravet, S., Piedra, J., García de Herreros, A., and Duñach, M. (1999). Regulation of E-cadherin/Catenin association by tyrosine phosphorylation. J. Biol. Chem. 274, 36734-36740.

Sakai-Kato, K., Ishiguro, A., Mikoshiba, K., Aruga, J., and Utsunomiya-Tate, N. (2008). CD spectra show the relational style between Zic-, Gli-, Glis-zinc finger protein and DNA. Biochim. Biophys. Acta - Proteins Proteomics 1784, 1011-1019.

Schwarz-Romond, T., Asbrand, C., Bakkers, J., Kühl, M., Schaeffer, H.-J., Huelsken, J., Behrens, J., Hammerschmidt, M., and Birchmeier, W. (2002). The ankyrin repeat protein Diversin recruits Casein kinase lepsilon to the beta -catenin degradation complex and acts in both canonical Wnt and Wnt/JNK signaling. Genes Dev. 16, 2073-2084.

Shafer, B., Onishi, K., Lo, C., Colakoglu, G., and Zou, Y. (2011). Vangl2 promotes Wnt/planar cell polarity-like signaling by antagonizing Dvl1mediated feedback inhibition in growth cone guidance. Dev. Cell 20,177-191. Statham, A.L., Strbenac, D., Coolen, M.W., Stirzaker, C., Clark, S.J., and Robinson, M.D. (2010). Repitools: an R package for the analysis of enrichment-based epigenomic data. Bioinformatics 26, 1662-1663. 
Stoeckli, E.T. (2018). Understanding axon guidance: are we nearly there yet? Development 145, dev151415.

Subramanian, A., Tamayo, P., Mootha, V.K., Mukherjee, S., Ebert, B.L., Gillette, M.A., Paulovich, A., Pomeroy, S.L., Golub, T.R., Lander, E.S., et al. (2005). Gene set enrichment analysis: a knowledge-based approach for interpreting genome-wide expression profiles. Proc. Natl. Acad. Sci. U. S. A. 102, 15545-15550.

TeSlaa, J.J., Keller, A.N., Nyholm, M.K., and Grinblat, Y. (2013a). Zebrafish

Zic2a and Zic2b regulate neural crest and craniofacial development. Dev.

Biol. 380, 73-86.

TeSlaa, J.J., Keller, A.N., Nyholm, M.K., and Grinblat, Y. (2013b). Zebrafish

Zic2a and Zic2b regulate neural crest and craniofacial development. Dev.

Biol. 380, 73-86.

Thorvaldsdóttir, H., Robinson, J.T., and Mesirov, J.P. (2013). Integrative Genomics Viewer (IGV): high-performance genomics data visualization and exploration. Brief. Bioinform. 14, 178-192.

Tissir, F., Bar, I., Jossin, Y., De Backer, O., and Goffinet, A.M. (2005).

Protocadherin Celsr3 is crucial in axonal tract development. Nat. Neurosci. 8, 451-457.

Tiveron, M.-C., Beclin, C., Murgan, S., Wild, S., Angelova, A., Marc, J., Coré, N., de Chevigny, A., Herrera, E., Bosio, A., et al. (2017). Zic-proteins are repressors of dopaminergic forebrain fate in mice and C. Elegans. J.

Neurosci. 37.

Valenta, T., Hausmann, G., and Basler, K. (2012). The many faces and functions of $\beta$-catenin. EMBO J. 31, 2714-2736. 
Williams, S.E., Mann, F., Erskine, L., Sakurai, T., Wei, S., Rossi, D.J., Gale, N.W., Holt, C.E., Mason, C.A., and Henkemeyer, M. (2003). Ephrin-B2 and EphB1 mediate retinal axon divergence at the optic chiasm. Neuron 39, 919935.

Wimmer-Kleikamp, S.H., Janes, P.W., Squire, A., Bastiaens, P.I.H., and Lackmann, M. (2004). Recruitment of Eph receptors into signaling clusters does not require ephrin contact. J. Cell Biol. 164, 661-666.

Wolf, A.M., Lyuksyutova, A.I., Fenstermaker, A.G., Shafer, B., Lo, C.G., and Zou, Y. (2008). Phosphatidylinositol-3-Kinase-Atypical Protein Kinase C Signaling Is Required for Wnt Attraction and Anterior-Posterior Axon Guidance. J. Neurosci. 28, 3456-3467.

Wrobel, C.N., Mutch, C.A., Swaminathan, S., Taketo, M.M., and Chenn, A. (2007). Persistent expression of stabilized $\beta$-catenin delays maturation of radial glial cells into intermediate progenitors. Dev. Biol. 309, 285-297. Xin, N., Benchabane, H., Tian, A., Nguyen, K., Klofas, L., and Ahmed, Y. (2011). Erect Wing facilitates context-dependent Wnt/Wingless signaling by recruiting the cell-specific Armadillo-TCF adaptor Earthbound to chromatin. Development 138, 4955-4967.

Ye, T., Krebs, A.R., Choukrallah, M.-A., Keime, C., Plewniak, F., Davidson, I., and Tora, L. (2011). seqMINER: an integrated ChIP-seq data interpretation platform. Nucleic Acids Res. 39, e35.

Yoshikawa, S., McKinnon, R.D., Kokel, M., and Thomas, J.B. (2003). Wntmediated axon guidance via the Drosophila derailed receptor. Nature 422, $583-588$.

Zhang, Y., Liu, T., Meyer, C.A., Eeckhoute, J., Johnson, D.S., Bernstein, B.E., 
Nussbaum, C., Myers, R.M., Brown, M., Li, W., et al. (2008). Model-based

Analysis of ChIP-Seq (MACS). Genome Biol. 9, R137.

Zhu, L.J., Gazin, C., Lawson, N.D., Pagès, H., Lin, S.M., Lapointe, D.S., and

Green, M.R. (2010). ChIPpeakAnno: a Bioconductor package to annotate

ChIP-seq and ChIP-chip data. BMC Bioinformatics 11, 237. 


\section{FIGURE LEGENDS}

Figure 1. Wnt5A is expressed at the midline and enhances axonal growth of contralateral axons.

(A) In situ hybridization for Wnt5a in coronal sections from E13.5, E15.5 and E17.5 embryos. Scale bar: $20 \mu \mathrm{M}$. (B) $\beta$-tubulin staining on retinal explants from E14.5 embryos cultured for 24 hours. Retinal explants from the central retina treated with recombinant Wnt5a protein display longer neurites compared with vehicle-treated explants. Scale bar: $100 \mu \mathrm{M}$. (C) Quantification of axonal length in explants treated with vehicle versus Wnt5a. Axonal length values in Wnt5a-treated explants $(n=25)$ were normalized to the mean value of axons treated with the vehicle $(n=31)$. $n=$ number of explants (Two-tailed Mann-Witney $U$ test, $p=0.007$ ). (D) Relative cumulative frequency histogram showing axonal length in explants growing in the presence of Wnt5a (gray, $\mathrm{n}=927$ ) or the vehicle (black, $\mathrm{n}=861$ ). Each dot represents an individual neurite. $n=$ number of axons from three biological replicates. (E) Immunohistochemistry for $\beta$ catenin in the growth cone of ganglion cells form contralateral axons treated for 1 hour with Wnt5a or vehicle. Note that Wnt5atreated cones occupy a larger area and show higher levels of $\beta$ catenin. Scale bar: $5 \mu \mathrm{M}$. (F, G) Quantification of the growth cone surface (vehicle $n=66$; Wnt5a $n=69$ ) and the levels of $\beta$ catenin (vehicle $n=81 ;$ Wnt5a $n=69$ ) in the cone of Wnt5a and vehicle treated retinal explants. Individual axon length and values for $\beta$ catenin fluorescence intensity (FI) from Wnt5a-treated growth cones were normalized to vehicle mean. $\beta$ catenin levels Two-tailed unpaired t-test, $\mathrm{P}<0.0001$. Results show mean $\pm \mathrm{SEM}$. 
Figure 2. $\beta$ catenin is necessary for midline crossing.

(A) Plasmids encoding EGFP plus control shRNA or shRNA against $\beta$ catenin (Ctnnb shRNAs) were electroporated into one eye of E13.5 embryos and EGFP-axons into the optic chiasm were analyzed at E18.5. Right panels are representative images of optic chiasms from embryos electroporated with Ctnnb shRNA or scramble shRNAs plasmids. Downregulation of $\beta$ catenin in contralaterally projecting neurons inhibits midline crossing. (B) Graphs represent the percent of embryos showing midline crossing defects after electroporation with scramble shRNA ( $n=10$; No Phenotype (NP)=87.5\%, Ectopic Ipsilateral projection $($ Ipsi $)=12,5 \%)$ or Ctnnb shRNAs $(n=42$; $N P=9.52 \% ;$ Ipsi $=42.86 \%$ and Stalled $=47.62 \%$ ) plasmids. (C) Summary of the experimental approach. (D) Representative immunohistochemistry for RFP and EGFP in wholemount E16.5 retinas electroporated at E13.5 with Top-RFand EGFP-, or $\triangle 90-\beta C$ atenin /Top-RFP- and EGFP-encoding plasmids show that canonical Wnt signaling is not activated in cRGCs at the time that visual axons transverse the midline. The experiment was repeated at least 3 times for each condition with similar results.

Figure 3. The axons of Zic2-expressing neurons do not show a positive response to Wnt5a.

(A) Upper panels, show the experimental approach used to assess the response of Zic2 expressing-neurons to Wnt5a. Retinal explants from E14.5 embryos electroporated at E13.5 with EGFP- or Zic2/EGFP-encoding plasmids were isolated and cultured with or without Wnt5a. The bottom images are retinal explants from electroporated embryos incubated with 
Wnt5a or vehicle. Scale bar: $200 \mu \mathrm{M}$ (B) Quantification of axonal length in axons from RGCs expressing EGFP (Vehicle $n=30$, Wnt5a $n=26$ ) or Zic2/EGFP (Vehicle $n=17$, Wnt5a $n=18$ ) grown in the presence of Wnt5a or vehicle. In Wnt5a-treated explants, axon length values were normalized to the mean value of the axons in explants treated with the vehicle. Two-tailed unpaired t-test, EGFP p-value=0.003, Zic2 p-value=0.563. (C) Schema summarizing the experimental approach. Images show axons from representative retinal explants isolated from electroporated embryos that were cultured for 24 hours and exposed to Wnt5a or vehicle for 1 hour. Green arrow heads point out axons with growth cones smaller than 70 microns. Scale bar: $50 \mu \mathrm{M}$ (D) Quantification showing the percentage of growth cones smaller than 70 microns in Zic2-expressing explants incubated with Wnt5a or the vehicle (Vehicle $n=16 ;$ Wnt5a $n=22 ; P=0.0004$ ) (Two-tailed unpaired t-test $\left.{ }^{* * *} \mathrm{p}<0.001\right)$. Results from three biological replicates. Results show mean \pm SEM.

\section{Figure 4. Transcriptome analysis in RGCs transduced with Zic2}

(A) Scheme representing the experimental design of the RNA-seq screen. (B) Volcano plot showing differentially expressed genes (DEGs) 36 hours after Zic2 electroporation in contralateral RGCs. The name of relevant DEGs is indicated in the amplification inset. The significance value for the change in Zic2 is above the scale (P-adj = 0). (C) GO enrichment analysis of genes upregulated (top graphs) and downregulated (bottom graphs) after Zic2induced expression in RGCs. The bar graphs present the significance of the enrichment (right) and the number of genes involved (left). (D) Panther 
pathway enrichment analysis of genes upregulated (top graphs) and downregulated (bottom graphs) after Zic2-induced expression in RGCs. The bar graphs present the significance of the enrichment (right) and the number of genes involved (left). (E) GSEA of DEGs after Zic2-transduction of RGCs detects a non-random distribution of genes involved in Wnt signaling. The normalized enrichment score (NES) and FDR values are shown in the upper right corner of the graph.

\section{Figure 5. Zic2 regulates Wnt signaling genes}

(A) Distribution of Zic2 peaks across gene features. Most peaks locate in the proximity of the transcription start site (TSS). (B) Unbiased identification of TF binding motifs enriched in Zic2 peaks. The Venn diagram shows the copresence of the two main motifs detected in our screen. The three sector graphs show the distribution across gene features of the peaks containing motif $A$, motif $B$ and lacking both motifs. (C) Luciferase assay in HEK cells showing a stronger transactivation of the reporter gene driven by Zic2 recruitment by motif $A$ than by motif $B$ or Gli. Note that the three motifs produce a significant increase when compared to the control situation which is the reporter plasmid lacking the motifs (two-tailed unpaired t-test; * $p<0.05$; $\left.{ }^{* *} p<0.01\right)$. Data from three independent experiments were analyzed. Results show mean \pm SEM. (D) Heatmap of DEGs detected in our RNA-seq screen. The right column (yellow) highlights the genes detected in both the RNA-seq differential expression screen and the Chip-seq screen for Zic2-bound genes (in black). (E) Distribution of motif $A$ and $B$ in the common gene set. (F) Distribution of Zic2 binding across gene features in the common gene set. (G) 
GO and PANTHER enrichment analyses of the common gene set. The bar graphs present the significance of the enrichment (right) and the number of genes involved (left) (H) ChIP-seq and RNA-seq profiles for two relevant Wnt signaling genes downregulated by Zic2. (I) ChIP-seq and RNA-seq profiles for four relevant Wnt signaling genes upregulated by Zic2.

\section{Figure 6. Zic2 causes accumulation of Bcatenin in RGCs to disrupt} midline crossing.

(A) In situ hybridization for the Wnt receptor Fzd8 in a coronal section of an E16.5 mouse retina (blue arrow and higher magnification of the square are at the bottom. (B) Immunofluorescence for Apc2 and $\beta$ catenin in the growth cone of axons growing from explants electroporated with EGFP- or Zic2encoding plasmids. Zic2-expressing retinal ganglion cell axons show reduced levels of the Apc2 protein and concomitant increased levels of $\beta$ catenin. Scale bar: $10 \mu \mathrm{M}$. (C) Quantification of immunofluorescence intensity for Apc2 (upper graph) ( $\mathrm{n}_{\text {eGFP }}=41, \mathrm{n}_{\mathrm{Zic} 2}=30, \mathrm{p}=0.0022$ ) and $\beta$ catenin (lower graph) $\left(\mathrm{n}_{\mathrm{eGFP}}=81, \mathrm{n}_{\mathrm{Zic} 2}=62, \mathrm{p}<0.0001\right)$. (D) Representative immunohistochemistry for RFP and EGFP in wholemount E16.5 retinas electroporated at E13.5 with plasmids encoding $\Delta 90-\beta$ Catenin plus Top-RFP and EGFP, Zic2 plus TopRFP and EGFP, or $\Delta 90-\beta$ Catenin/Top-RFP/EGFP and Zic2. Images at the right corners depict targeted/EGFP cells in whole mounted retina. RFP staining shows activation of the canonical Wnt signaling. Despite the higher levels of $\beta$ catenin observed in Zic2-expressing cells versus the controls, the canonical Wnt signaling is not activated. Instead, Zic2 is able to dampen the canonical Wnt signaling in neurons that overexpress a stabilized form of 


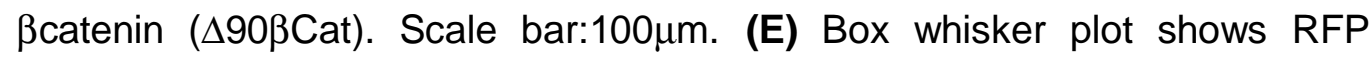
fluorescence in wholemount electroporated retinas normalized to control. $\Delta 90$ $\beta$ Catenin/Top-RFP/EGFP data: $n=675, \quad$ Mean $=1.076 \quad \mathrm{SE}=0.0625 \%$ percentile $=0.0$ Median $=0.21,75 \%$ percentile $=1.772 . \Delta 90-\beta$ Catenin $/$ Top RFP/EGFP/Zic2 data: $n=649$, Mean $=0.53, S E=0.04,25 \%$ percentile $=0.00$ Median $=0.13, \quad 75 \%$ percentile $=0.43 . \quad$ (Two-tailed unpaired $t$-test $\left.{ }^{* * * *} p<0.0001\right)$. Results from three biological replicates. Results show mean \pm SEM. (F) Optic chiasms from E16.5 embryos electroporated with plasmids encoding for $\beta$ catenin or the stabilized form of this protein $\Delta 90-\beta$ catenin- $\Delta \mathrm{CT}$ (transcriptionally inactive). Scale bar: $100 \mu \mathrm{M}$ (G) Quantification showing the percentage of contralaterally projecting axons normalized to the total number of EGFP axons at the chiasm for each condition ( $\beta$ cat $n=10 ; \Delta 90-\beta$ cat- $\Delta$ CT $\mathrm{n}=9$ ) (Two-tailed unpaired t-test; ${ }^{* * *} \mathrm{p}<0.0001$. Results show mean $\pm \mathrm{SEM}$.

\section{Figure 7. The knockdown of $\beta$ catenin facilitates EphB1-mediated axon}

\section{steering}

(A) Optic chiasms from E16.5 embryos electroporated at E13.5 with plasmids encoding EGFP plus EphB1 alone or together with plasmids bearing shRNA

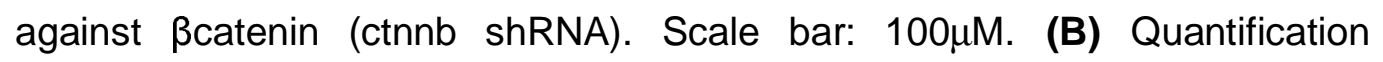
showing the percentage of ipsilaterally projecting axons in each condition normalized to the total number of EGFP axons at the chiasm (Zic2 $n=23$; EphB1 n=16; EphB1/ctnnb shRNA n=28) (Two-tailed unpaired t-test; ** $p<0.01$, $\left.{ }^{* * * *} p<0.0001\right)$. Results show mean \pm SEM. (C) Detection of $\beta$ catenin in the immunoprecipitation of tyrosine-phosphorylated proteins from GFP-, EphB1and EphB1- $\Delta$ CT-transfected cells. (D) Detection of tyrosine-phosphorylation 
in ßcatenin immunoprecipitated from GFP-, EphB1- and EphB1- $\triangle C T$ transfected cells. (E) Detection of Y654ßcatenin in protein extracts from GFPand EphB1-transfected cells. (F) Immunohistochemistry using antibodies to Y654ßcatenin and total ßcatenin in Hek293 cells transfected with EGFP or EphB1. Scale bar: $10 \mu \mathrm{M}$. (G) Percentage of phosphoY654ßcatenin cells on EGFP-expressing cells. Eleven ROls were quantified from three independent experiments for each condition. Two-tailed Mann Whitney-test *** $0<0.0001$. Results show mean \pm SEM. (H) Quantification of the area occupied by individual cells transfected with EGFP alone or EphB1 plus EGFP-encoding plasmids (EphB1 n=24; EphB1/ctnnb shRNA n=24). Two-tailed unpaired t-test ${ }^{* * *} p<0.001$. Results show mean \pm SEM. (I) Working Model. As the axon grows in the absence of Wnt5a, cadherins are constantly being recycled from the plasma membrane. When contralaterally projecting axons reach the midline, the binding of $\mathrm{Fz}$ receptors to Wnt5a triggers the local accumulation of $\beta$ catenin linking cadherins and actin microtubules to promote cytoskeleton stabilization and facilitating midline crossing. In ipsilaterally projecting neurons, Zic2 activates a different set of Wnt receptors and other intracellular Wnt proteins at the time that it downregulates Apc2 to favor accumulation of Bcatenin. Asymmetric phosphorylation of $\beta$ catenin mediated by activation of EphB1 (also induced by Zic2) through ephrinB2 binding, breaks cadherin/actin complexes and induces local microtubule destabilization.

\section{MATERIAL AND METHODS}

\section{Mice}


All experiments were performed using embryos from C57/DBA F1 hybrids. Mice were kept in a timed pregnancy breeding colony at the Instituto de Neurociencias (IN). The animal protocols were approved by the IN Animal Care and Use Committee and met European and Spanish regulations.

\section{Cell culture, plasmids and luciferase assay}

HEK293 cells (ATCC® CRL-15736 ${ }^{\mathrm{TM}}$ ) were cultured according to standard conditions. For luciferase assays, cells were transfected using Lipofectamine 2000 (Invitrogen) according to manufacturer' guidelines. Complementary primers containing Zic2 binding motifs A or B were cloned in pGL3-basic (See Supplementary methods for sequences) and co-transfected with or without CAG-Zic2 plasmid in conjunction with a thymidine-kinase (TK) promoter- $\beta$ Gal. Cell lysates were harvested the day after and luciferase and $\beta$ galactosidase activities were measured using Luciferase Reporter and BetaGlo Assay Systems (Promega) following the manufacturer's guidelines. Luciferase activity of all transfections was normalized to $\beta$-Gal activity.

\section{In utero electroporation and quantification}

Time-pregnant mouse females were anesthetized with a classic small animal anesthesia (isoflurane) system (WPI, USA). In utero electroporation was performed as described in García-Frigola et al. (2008). Plasmids with pCAGZic2, pCAG- $\triangle 90-\beta C$ atenin-GFP (Addgene 26645) pCAG-Full- $\beta$ catenin-GFP, pCAG- $\Delta 90-\beta C$ atenin- $\Delta$ CT-GFP, pCAG-EphB1, Top-RFP were injected at $1 \mu \mathrm{g} / \mu \mathrm{l}$ and pSilencer-shCtnnb1 and pSilencer-control at $2 \mu \mathrm{g} / \mu \mathrm{l} . \mathrm{pCAG}-\mathrm{GFP}$ plasmids were co-injected at $0.5 \mu \mathrm{g} / \mu \mathrm{l}$. pCAG- $\Delta 90-\beta C$ atenin- $\Delta$ CT-GFP and 
pCAG-Full $\beta$ Catenin-GFP were obtained from manipulation of the CAG- $\Delta 90$ $\beta$ Catenin-GFP (See Supplementary Methods for details). Fiji software was used to quantify ipsi and ipsilateral projections. Briefly, mean fluorescent intensity from three linear ROls drawn perpendicularly on each optic tract (OTF) was measured and background from a very proximal area was rested to each measure. The \% of ipsilateral projection was determined for each individual embryo by applying the following formula: \% Ipsis= (iOTF x100)/(iOTF+cOTF). Statistical analyses were performed with GraphPad Prism 6.0 (GraphPad software, Inc, La Jolla, CA).

\section{Retinal explant cultures and immunohistochemistry}

Retinal explants from E14.5 WT or electroporated embryos were plated on glass bottom microwell dishes (MatTek) coated with poly-L-lysine $0.01 \%$ and laminin $(20 \mu \mathrm{g} / \mathrm{ml})$. Culture media was DMEM:F12/Neurobasal media (Gibco TM) with $0.4 \%$ of methylcellulose with growth supplements $\mathrm{N}-2$ and B-27 and antibiotics Pen/Strep. For axonal growth analysis recombinant Wnt5a at $100 \mathrm{ng} / \mathrm{ml}$ or Wnt5a reconstitution buffer as a vehicle was added to the medium. For acute responses, retinal explants were exposed to recombinant Wnt5a at 200ng/ml for 1 hour.

Immunohistochemistry was performed on retinal explants fixed with pre-warmed $4 \%$ PFA in PBS at $37^{\circ} \mathrm{C}$ for $20 \mathrm{~min}$. Explants were permeabilized with $0.025 \%$ Triton X-100, blocked with horse serum and incubated with the specified antibody at $4^{\circ} \mathrm{C}$ overnight. Fluorescence microscopy was performed using a Leica confocal microscope SPEII. Area and fluorescence intensities at 
the growth cones were quantified by Fiji software using maximum intensity zprojection.

\section{In situ hybridization}

Heads of embryos from E13.5 to E17.5 were dissected in cold PBS $1 \mathrm{X}$ and fixed in 4\% PFA overnight. Coronal vibrosections (optic chiasms) or criosections (retinas) were obtained and in situ hybridization with specific antisense riboprobes for different Wnts and Wnt receptors (gift of Prof. P. Bovolenta). Images were captured with a Leica DM2500 equipped with a Leica DFC7000T camera and Leica Application Suite. Version 4.10.0 Software.

\section{RNA-seq, ChIP-seq and bioinformatic analyses}

RNA-seq: RGCs from E13 electroporated retinas were isolated $36 \mathrm{~h}$ postelectroporation by cell sorting. Isolated retinas were enzymatically dissociated in a mixture of collagenase/Trypsin and BSA for 20 minutes at $37^{\circ} \mathrm{C}$ followed by mechanical dissociation. Single cell suspension was filtered and resuspended in cold HBSS medium supplemented with $20 \%$ FBS. After cell sorting, cells were centrifuged and frozen. Total RNA extraction was performed with Arcturus ${ }^{\circledR}$ Picopure ${ }^{\circledR}$ RNA isolation Kit (ThermoFisher Scientific). The samples were sequenced according to the manufacturer instructions in a HiSeq Sequencing v4 Chemistry (Illumina, Inc). Briefly, RNA-seq reads were mapped to the mouse genome (Mus_musculus.GRCm.38.83) using STAR (v2.5.0c) (Dobin et al., 2013). Quality control of the raw data was performed with FastQC 
(http://www.bioinformatics.babraham.ac.uk/projects/fastqc/). Library sizes were between 41 and 75 million single reads. Samtools (v1.3.1) were used to handle BAM files ( $\mathrm{Li}$ et al., 2009a). To retrieve differentially expressed genes (DEG), mapped reads were counted with HTSeq v0.6.1 (Anders et al., 2015) with the following parameters: -s reverse -i gene_id and with a gtf file reference of GRCm38.83. Read count tables were analyzed using DeSeq2 v1.10.0 (Love et al., 2014). Analysis and preprocessing of data were performed with custom scripts using R (https://cran.r-project.org/) (v3.4.3"Kite-Eating Tree") statistical computing and graphics, and bioconductor v3.2 (Bioclnstaller 1.20.3) (Huber et al., 2015). Genes were considered differentially expressed at Benjamini-Hochberg $(\mathrm{BH})$ adjusted $p$ value $\square<\square 0.1$ Significantly upregulated and downregulated genes were visualized with IGV (v2.3.72) (Thorvaldsdóttir et al., 2013). GO enrichment analyses were performed using the platform Panther (Mi et al., 2019), with Fisher's exact test and with the Padj correction, obtaining the top terms using the filters by ratio enrichment $>2$, number of GO family group genes between 3 and 2000, number of enrichment genes $>3$, and Padj $<0.1$. The gene set enrichment analysis was obtained with GSEA v3.0 (Subramanian et al., 2005).

\begin{tabular}{lrccc} 
Sample & Library type & № of reads & \multicolumn{2}{c}{ Type pf sequencing Read length } \\
GFP1 & RNAseq & 43381301 & Single end & 50 \\
GFP2 & RNAseq & 41842837 & Single end & 50 \\
GFP3 & RNAseq & 46718303 & Single end & 50 \\
Zic2. 1 & RNAseq & 45279883 & Single end & 50 \\
Zic2.2 & RNAseq & 34371605 & Single end & 50
\end{tabular}


$\begin{array}{llll}\text { Zic2.3 } & \text { RNAseq } & 76525940 & \text { Single end }\end{array}$

Datasets can be accessed at the GEO repository (GSE133492).

ChIP-seq: Whole retinas or spinal cords were dissected from embryos at E16, chopped, crosslinked with 1\% PFA at room temperature for 20 minutes and quenched with glycine. Then, chromatin was sheared using a bioruptor sonicator (Diagenode) and immunoprecipitated as described in STAR Methods. Breafly, sheared chromatin was diluted and incubated overnight at $4^{\circ} \mathrm{C}$ with the specific antibody against mouse Zic2 (Millipore, AB15392) or IgG isotype control pre-immune serum (Abcam, ab27478). Immunoprecipitated chromatin was purified with Qiaquick PCR Purification Kit (Quiagen). To reduce biological variability, for each independent sample, chromatin was obtained by pooling tissue from several mice (retina, 176 mice; spinal cord, 68 mice). NGS Libraries were prepared from purified DNA from anti-zic2 ChIP (Zic2, IgG pre-immune serum) and input samples according to manufacturer instructions (Illumina). Libraries were single-end sequenced in HiSeq2000 apparatus using Flow Cell v3 chemistry (read length: 1 x 50 bp). Information on library preparation method, size of the libraries, and mapping to reference genome can be found at the end of this section. Quality control of the raw data was performed with FastQC (http://www.bioinformatics.babraham.ac.uk/projects/fastqc/). Libraries aligned to the mouse genome (mm9, NCBI assembly M37) using BurrousWheeler Alignment Tools (BWA) (v0.5.9) (Li and Durbin, 2010) and further processed using samtools (v0.1.17) (Li et al., 2009b) and bedtools (v2.19.0) (Quina, 2005). Additional quality control analyses on aligned sequences from of ChIP and input samples were performed using the $\mathrm{R}$ package 
Repitools (Statham et al., 2010). Peak calling for Zic2 ChIP-seq was (Li and Durbin, 2010) performed using MACS2 (v1.4.2) (Zhang et al., 2008) with the following parameters: -p 1.00e-05 -bw 300 -m 10,30. Read counts on aligned bam files were obtained using featureCounts (Rsubread v1.12.6) (Liao et al., 2014). Further data processing was performed with custom scripts in the $R$ programming language (https://cran.r-project.org/). De novo DNA motif discovery at Zic2-bound regions was performed using Homer software (Heinz et al., 2010) and MEME suite (Bailey et al., 2009), in an area of 151 bp (average genomic fragment length) around each peak summit. GO enrichment analyses were performed using the platform Panther, with Fisher's exact test and with the Benjamini-Hochberg False Discovery Rate for multiple test correction for the nominal $p$ values. GO top terms were obtained using the following filters: Padj $<0.1$, ratio enrichment $>2$, number of genes in enriched term $>3$, number of GO family group genes between 3 and 2000. Heatmaps of ChIP-seq read density and aggregate density plots were performed using SeqMiner (v1.3) (Ye et al., 2011) and R custom scripts. ChIP-seq peaks were annotated using ChIPpeakAnno (Zhu et al., 2010). ChIP-seq tracks were visualized using IGV (v2.3.72) (Robinson et al., 2011).

Sample Library type № of reads Type pf sequencing Read length

$\begin{array}{lllll}\text { Input_dSCN } & \text { ChIP DNA } & 46419753 & \text { Single end } & 50 \\ \text { Zic2_dSCN } & \text { ChIP DNA } & 31047920 & \text { Single end } & 50 \\ \text { Input_RGCs } & \text { ChIP DNA } & 94319654 & \text { Single end } & 50 \\ \text { Zic2_RGCs } & \text { ChIP DNA } & 64787935 & \text { Single end } & 50\end{array}$

Datasets can be accessed at the GEO repository (GSE133492). 


\section{Immunoprecipitation, mass spectrometry and Western-Blot}

HEK293 cells were transfected with pCAG-FullßCatenin-GFP or pCAGFullßCatenin-GFP/pCAG-EphB1 and isolated by cell sorting 48 hours posttransfection. Total protein was extracted in RIPA buffer with protease and phosphatase inhibitors. To obtain a phosphotyrosine-enriched ßcatenin sample a tandem enrichment strategy was used. First immunoprecipitation was performed with an anti-phosphotyrosine antibody, protein-G bounded proteins were eluted with phenyl-phosphate $(100 \mathrm{mM})$ and then immunprecipitated with anti- $\beta$ Catenin antibody. Samples were analyzed by mass spectrometry. Protein Identification by LC/MS/MS (LTQ-OrbitrapVelos) was carried out in the 'CBMSO Protein Chemistry Facility, that belongs to ProteoRed, PRB2-ISCIII, supported by grant PT13/0001.

\section{Data Collection and Analysis}

Data collection has been performed using the following equipment: FACS Aria2, Illumina NovaSeq; Leica confocal microscope SPEII; Leica DM2500; Leica DFC7000T camera and CUY21SC electroporator. Data analysis has been performed using the following softwares: Flowjo v10; Fiji software maximum intensity z-projection; Leica Application Suite (LAS) Software; Image J(v2), Microsoft Excel, (v16); FastQC (v.0.11.6), RSeQC (v2.6.4), fastq-dump (v2.3.5), Python 3.7.3, R software (v3.4.4) , Cutadapt (v1.18), Samtools (v1.9), Bedtools (v2.26.0), Rsubreads (v1.26.0), STAR(v2.5.0a), HTSeq (v0.7.2), DESeq2 (v1.10.0), Bowtie2 (v2.2.6), MACS2 (v2.1.0), ChIPpeakAnno (v.3.18), biomaRt (v.2.39), PANTHER (v14), IGV (v2.3.92), HOMER (v4.8), MEME Suite (v.5.0.3); GraphPad Prism Software (Version 
7.0) San Diego. Statistical analysis was performed as indicated in Figure Legends. Sample size was estimated according to data variance and correlation between biological replicates and distance to control condition. Each analysis was done in accordance to the sample size, sequencing depth and conditions. Reproducibility across replicate was very high. The measures applied to evaluate replicates were correlation among samples, variance, Euclidean classification, principal component analysis (PCA) and statistical tests that revealed not significant differences within the group. In the analyses in which a replicate was not available, analyses were supported by the use of internal controls and the sample was normalized and compared with samples from related conditions in which replicates were available (i.e., ANOVA, Desq2). 
A

Wnt5a mRNA

E13.5

B

E14.5
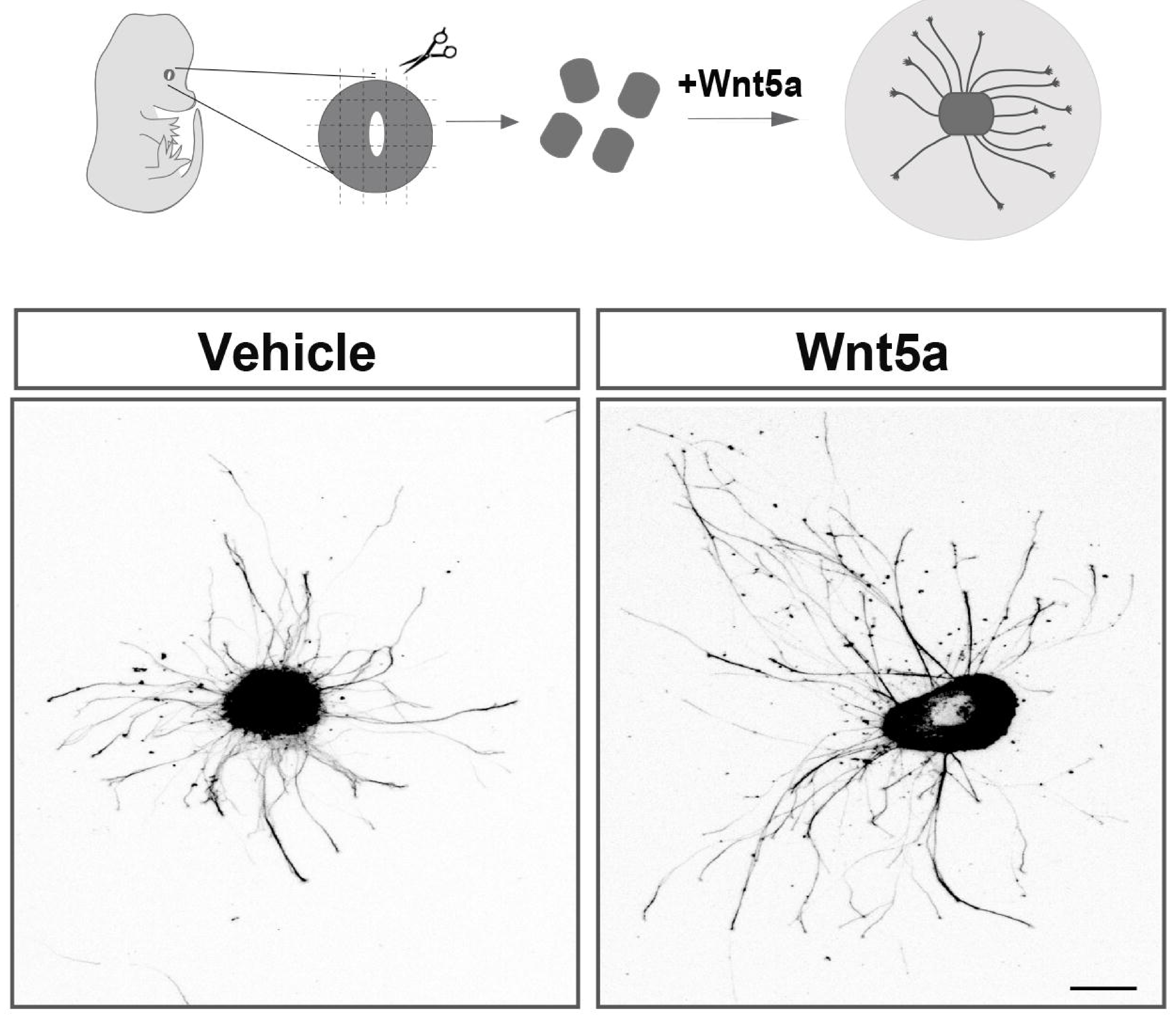

E

들

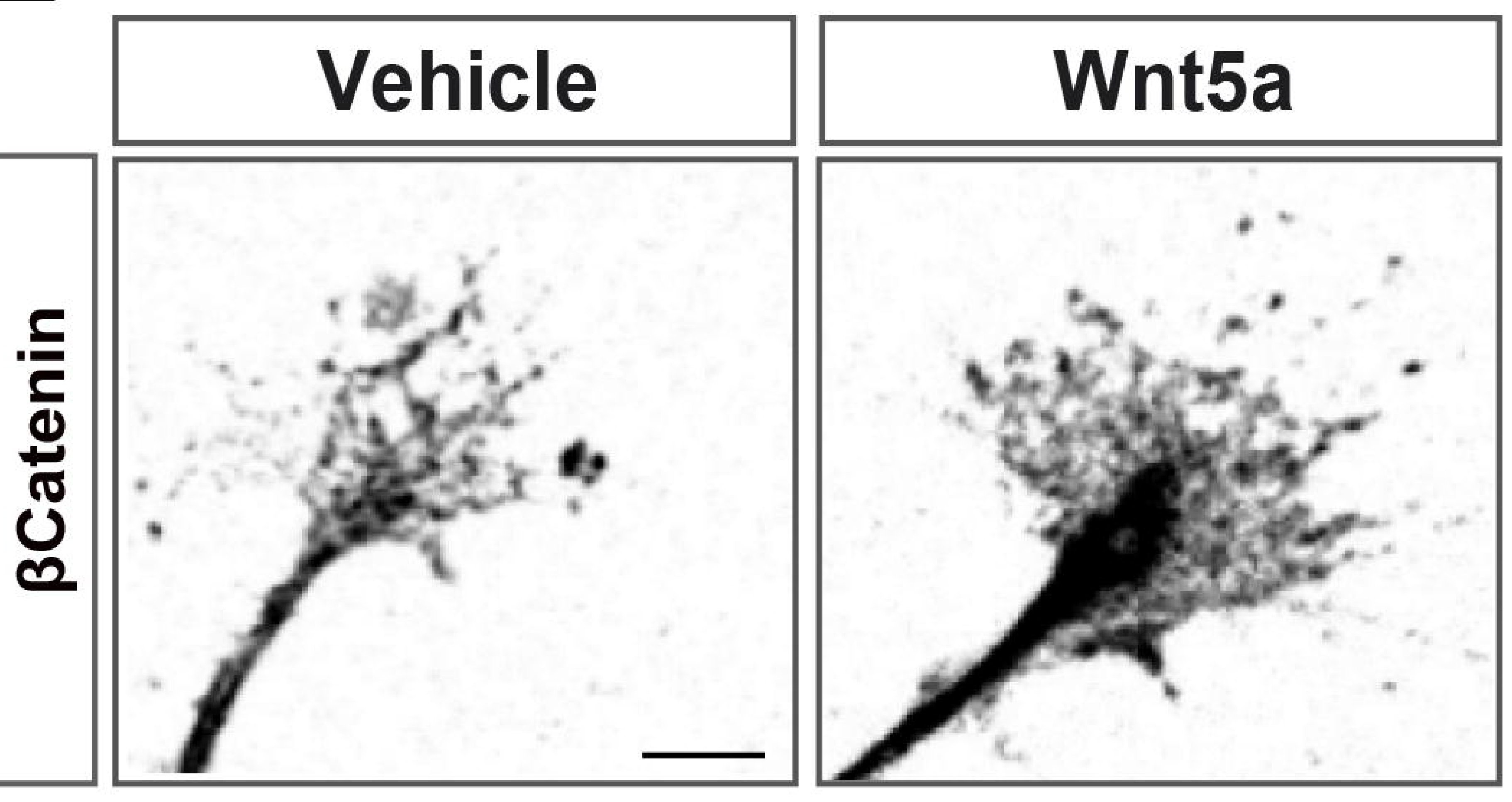

C

\section{E17.5}
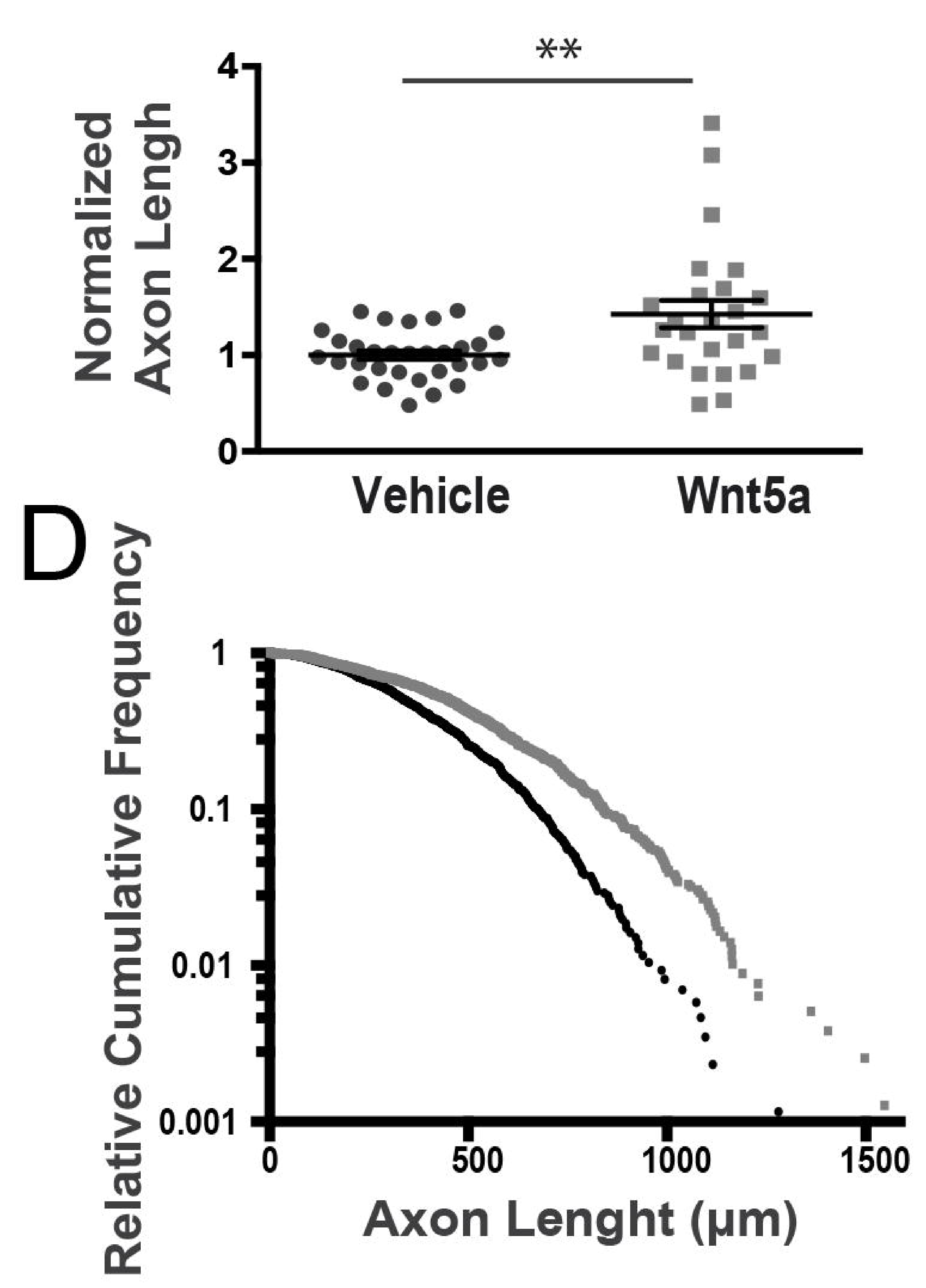

G

Figure 1

F

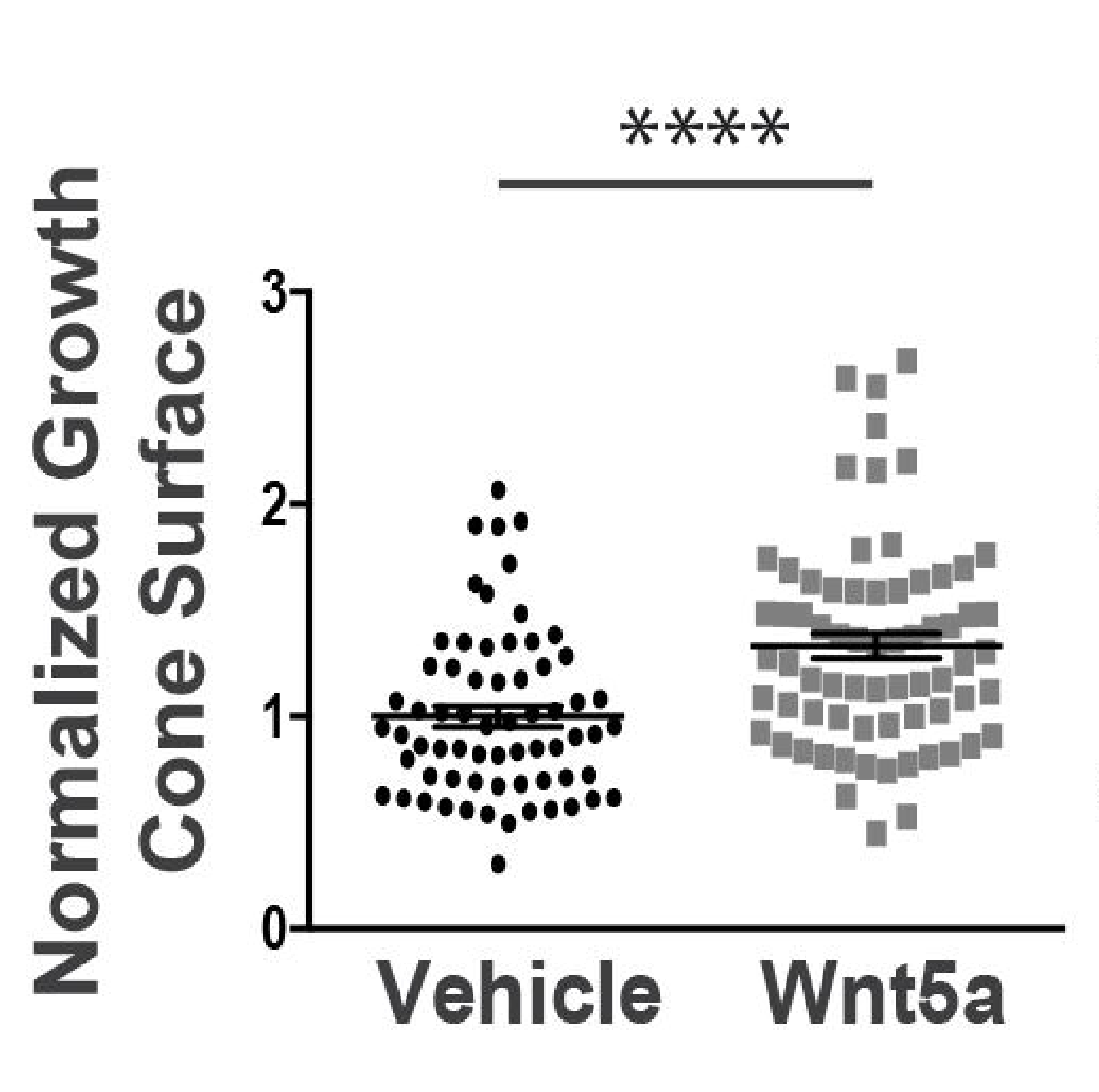

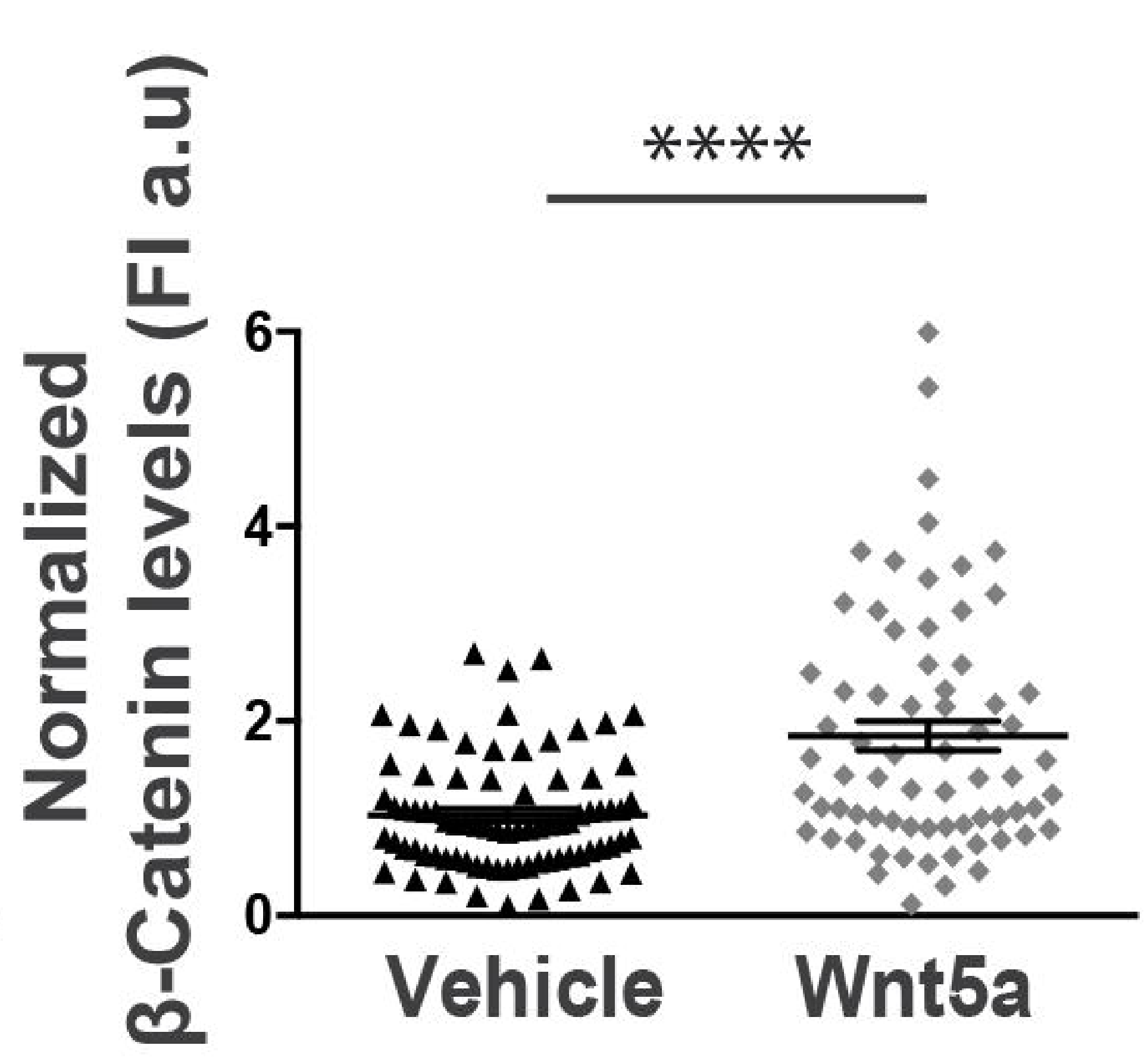




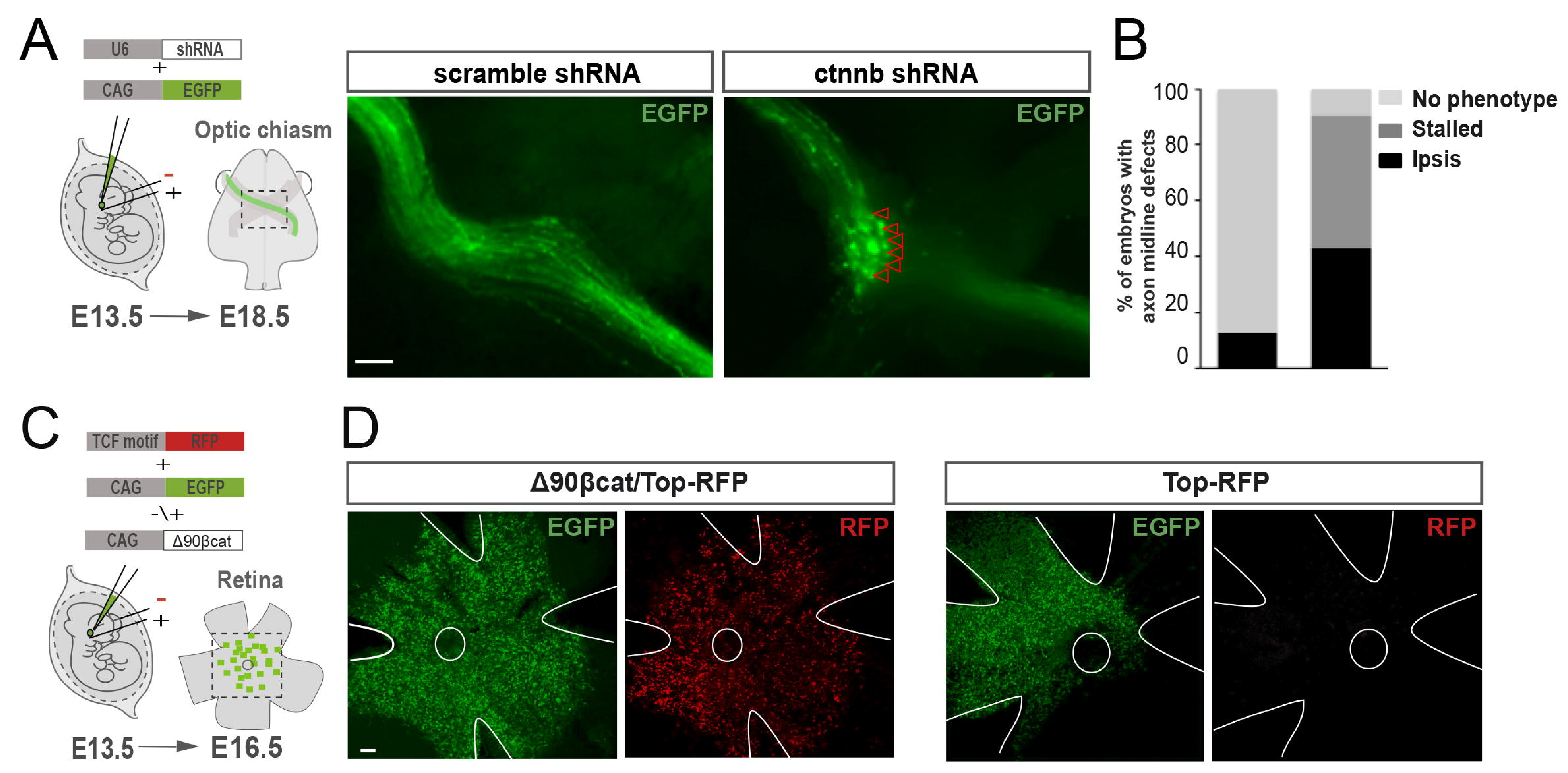

\section{Figure 2}


A

\section{E13.5}

B

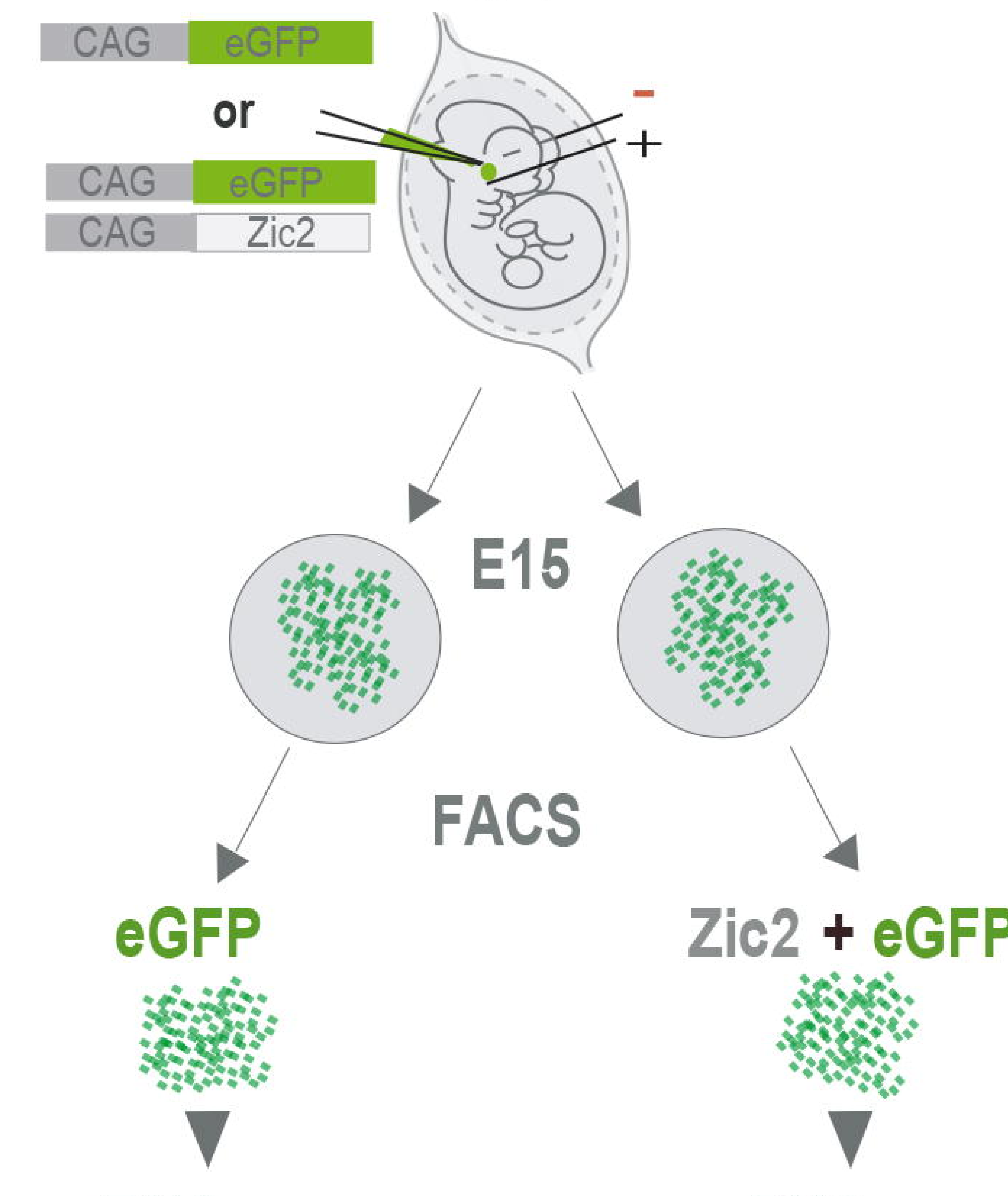

RNA-seq

C

RNA-seq

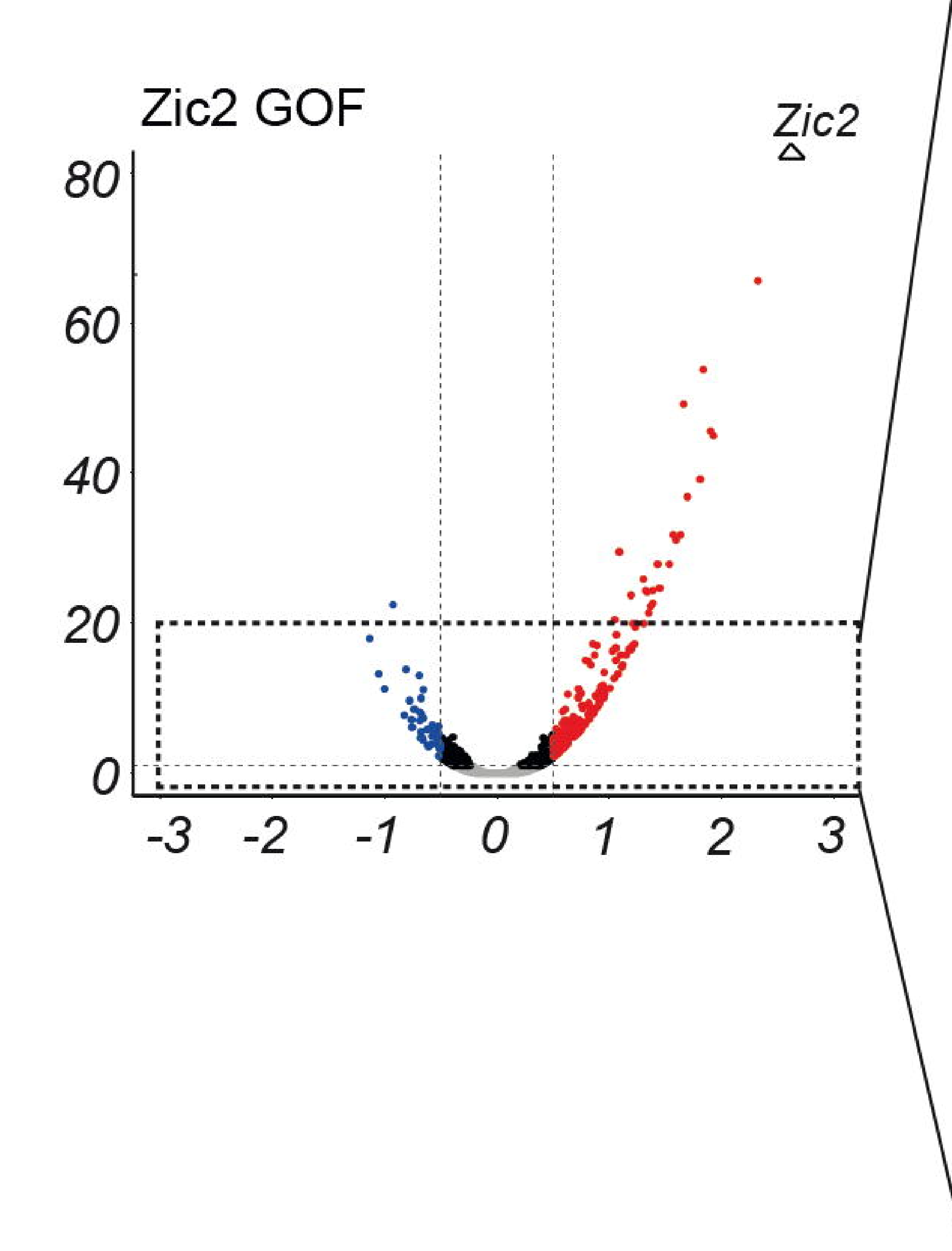

20 Padj < 0.1

Sign LFC $>0.5$

-Sign LFC $<0.5$.
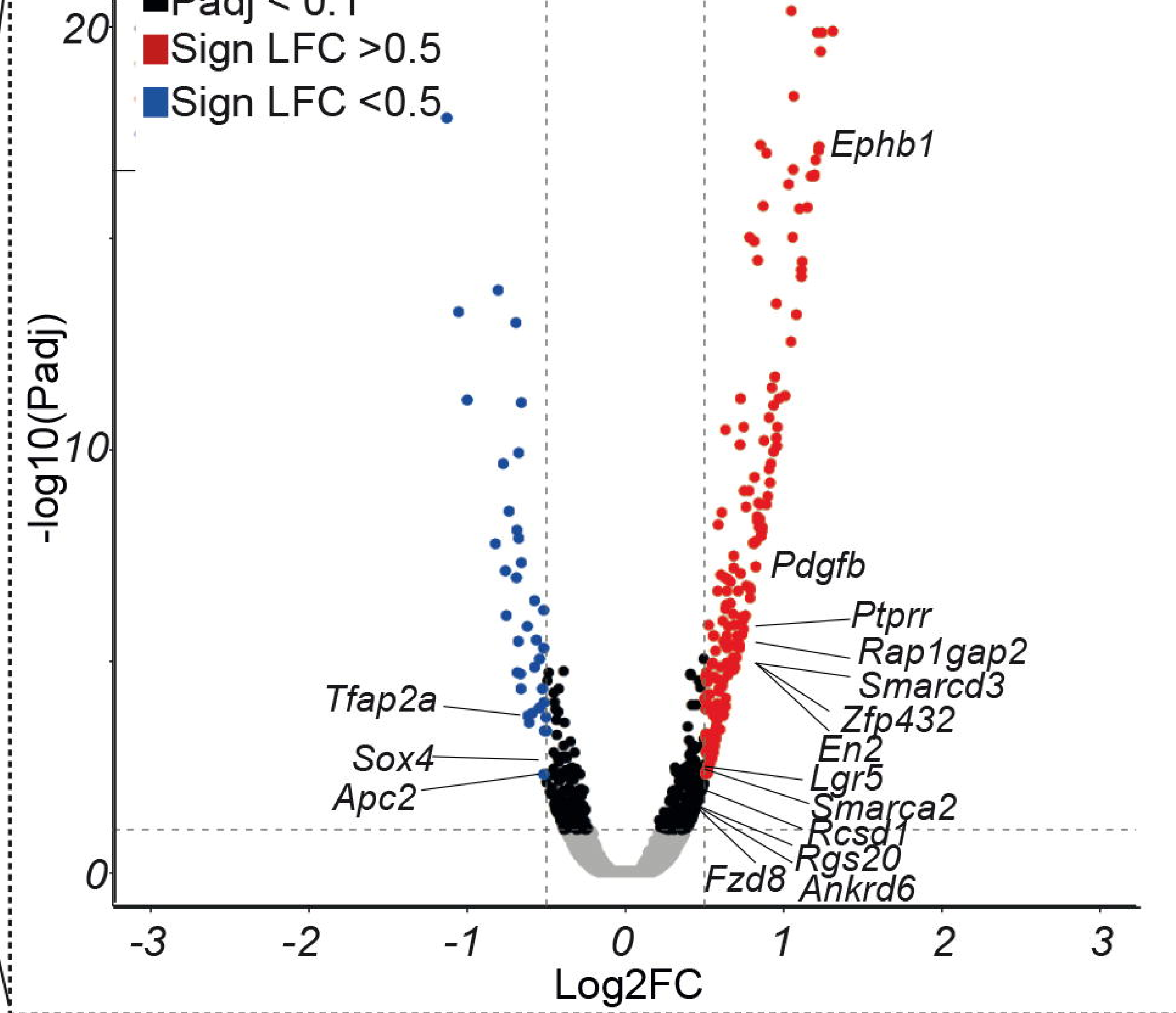

D Panther pathways

Upregulated

GO biological process

transmemb. Recept. Prot. Tyr. kinase sign. Path. neuron differentiation regulation of membrane potential cellular response to endogenous stimulus modulation of chemical synaptic transmission synaptic transmission glutamatergic regulation of neuron projection development protein kinase B signaling

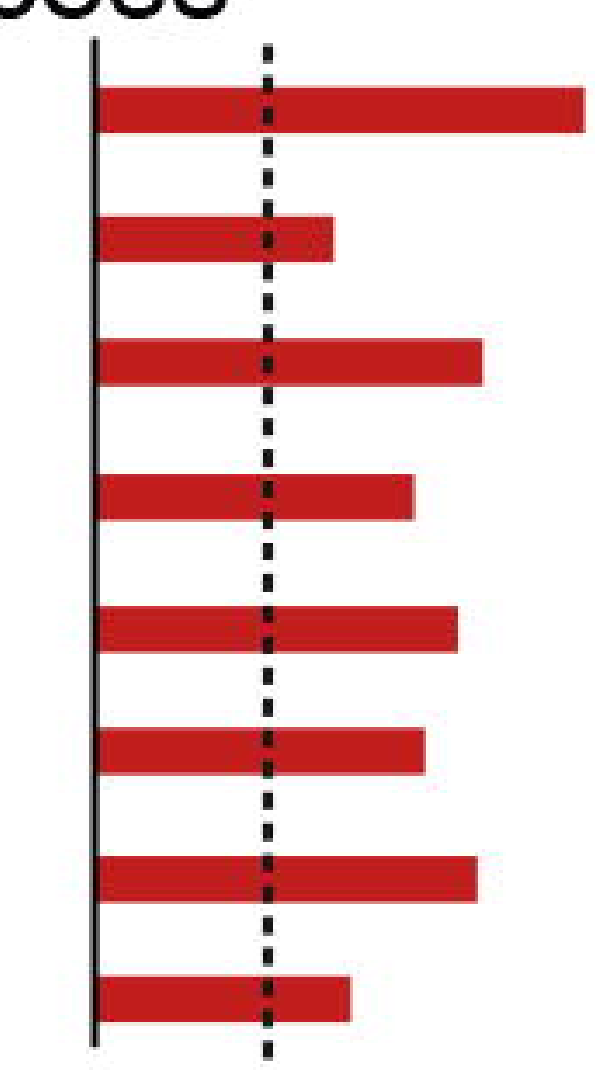

GO cellular component

postsynaptic membrane erminal bouton ionotropic glutamate receptor complex synaptic vesicle membrane cell-cell adherens junction

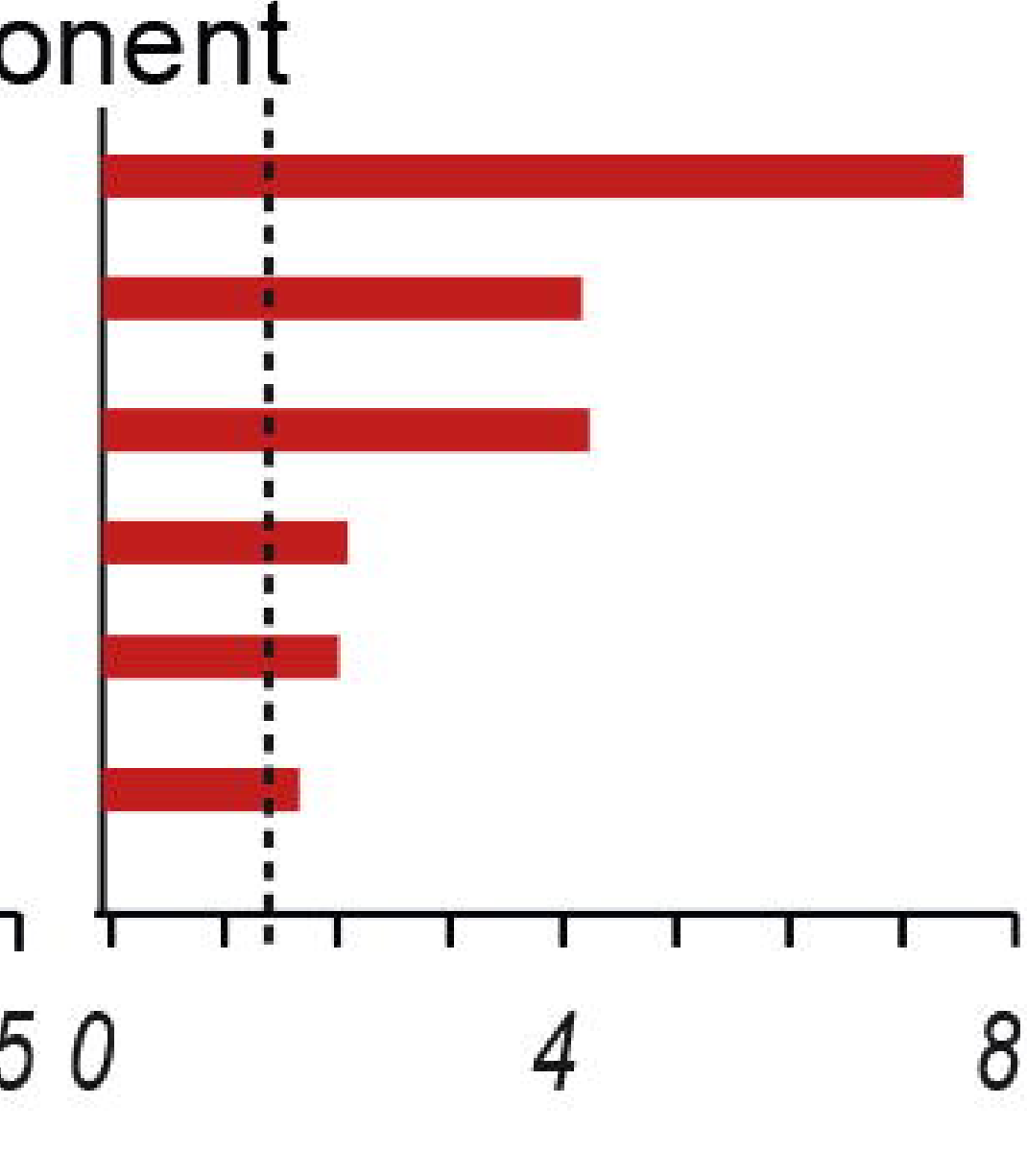

Downregulated

GO biological process

transcription by RNAPI regulation of transcription by RNAPII

cell surface receptor sign. path. chemical synaptic transmission

actin cytoskeleton organization axon guidance regulation of cell differentiation cell fate specification
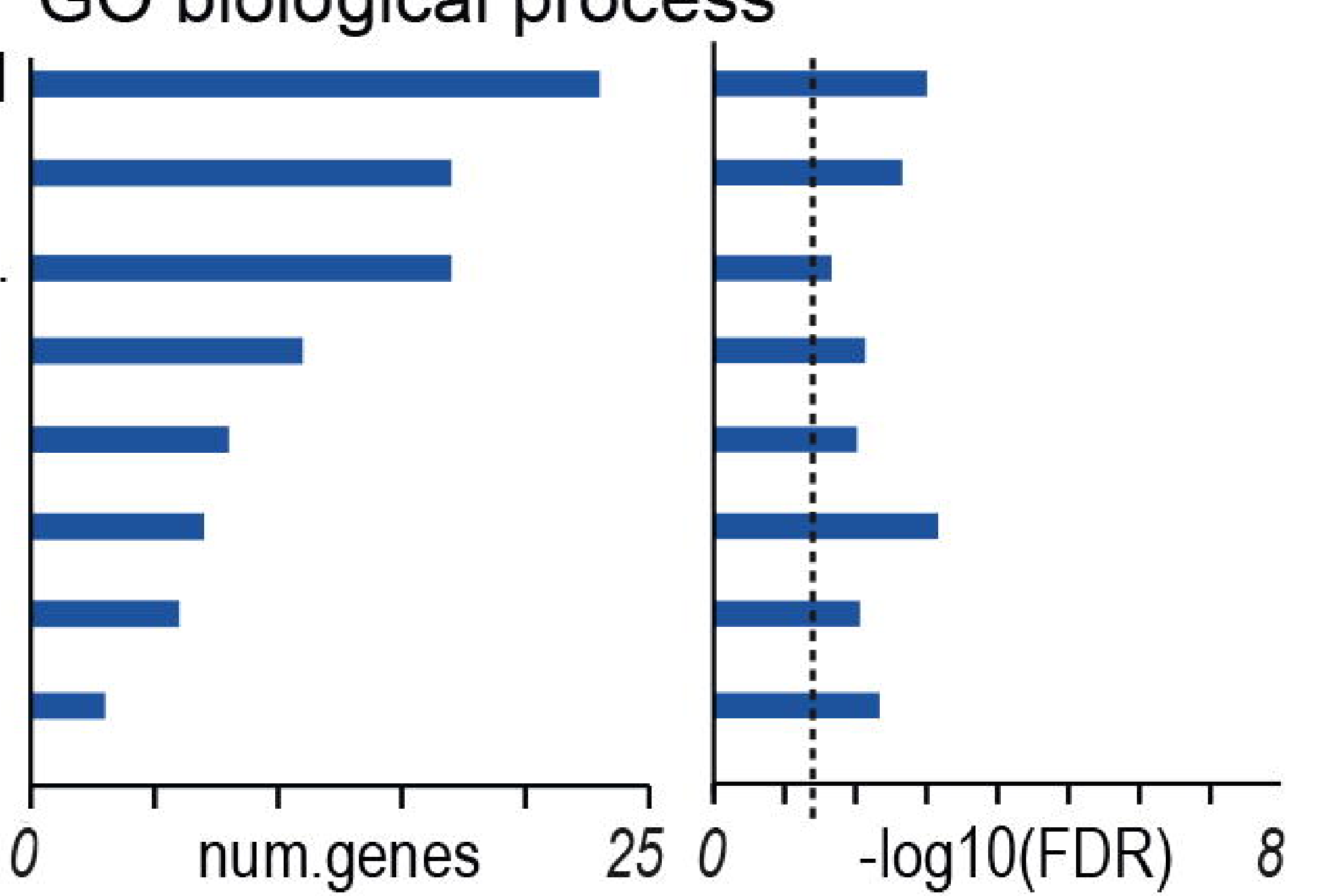

\section{Upregulated}

Gonadotropin-releasing hormone receptor path. Heterotrimeric G-protein sign. path. lonotropic glutamate recept. path. $5 \mathrm{HT} 2$ type receptor mediated sign. path Metabotropic glutamate receptor group III path. 5HT1 type receptor mediated sign. path. Oxytocin receptor mediated sign. path. 5HT4 type receptor mediated sign. path Axon guidance mediated by Slit/Robo

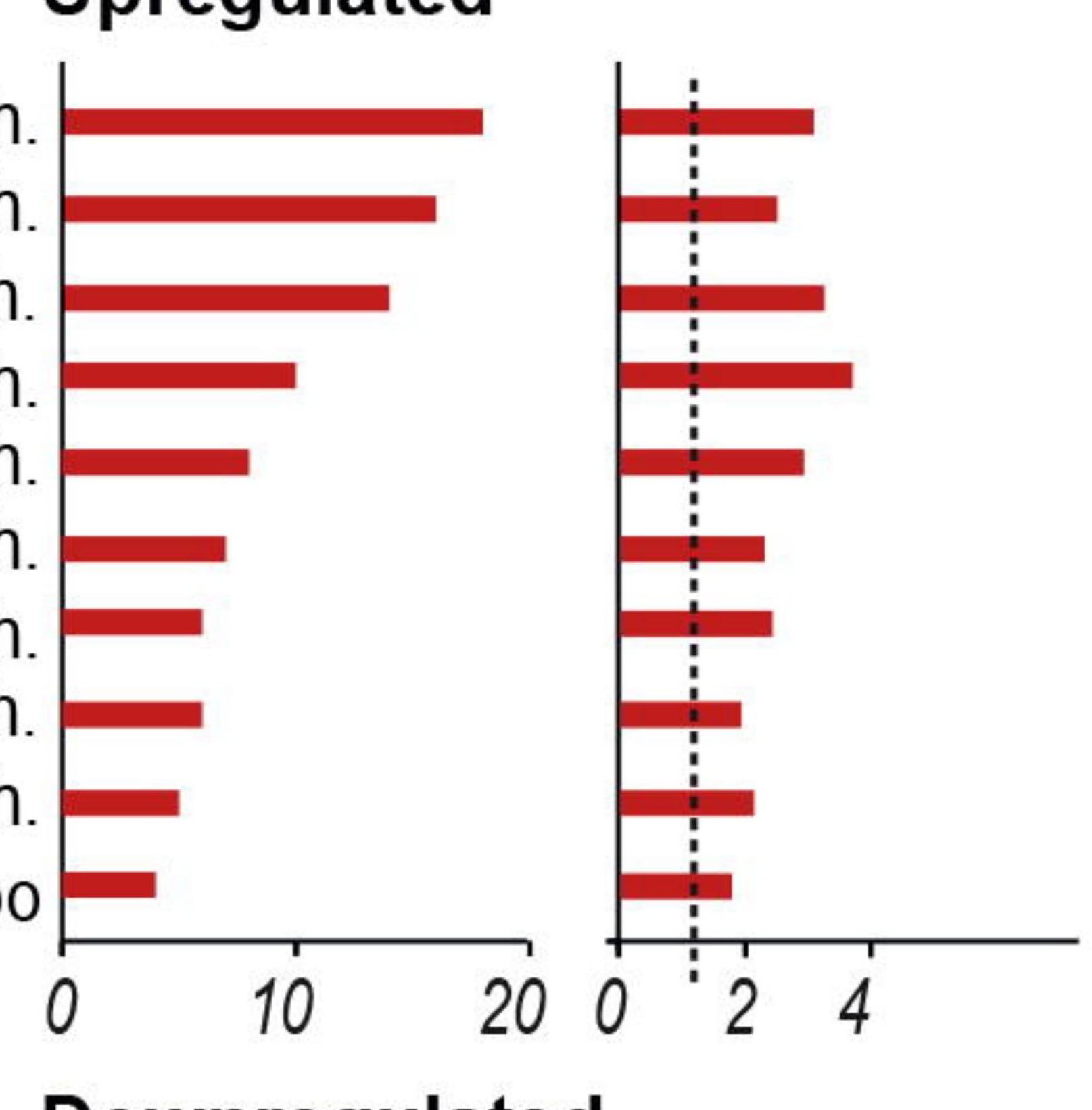

Downregulated

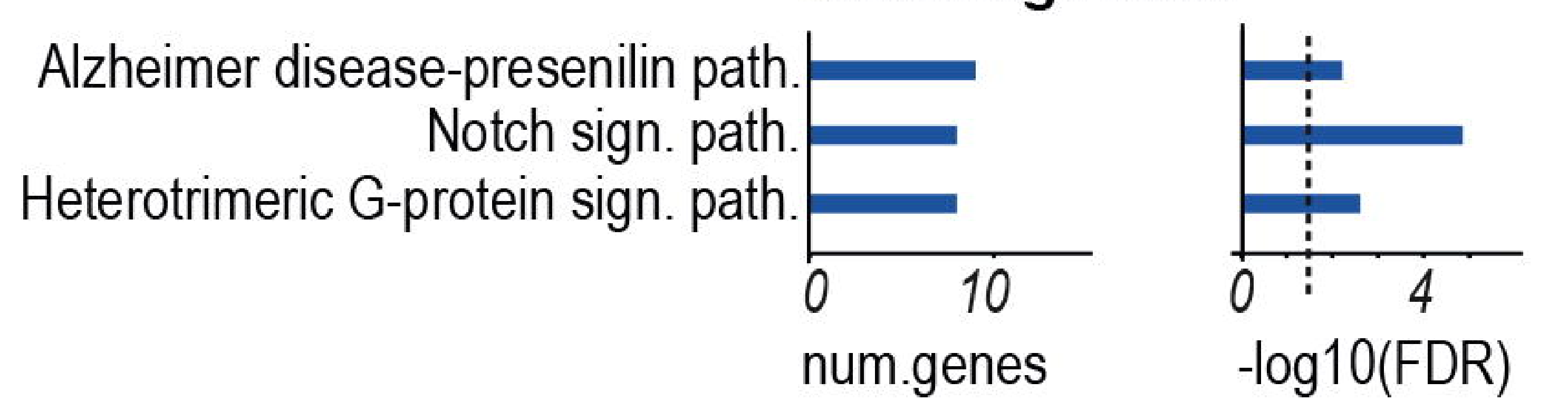

E Enrichment plot: KEGG WNT Signaling Pathway

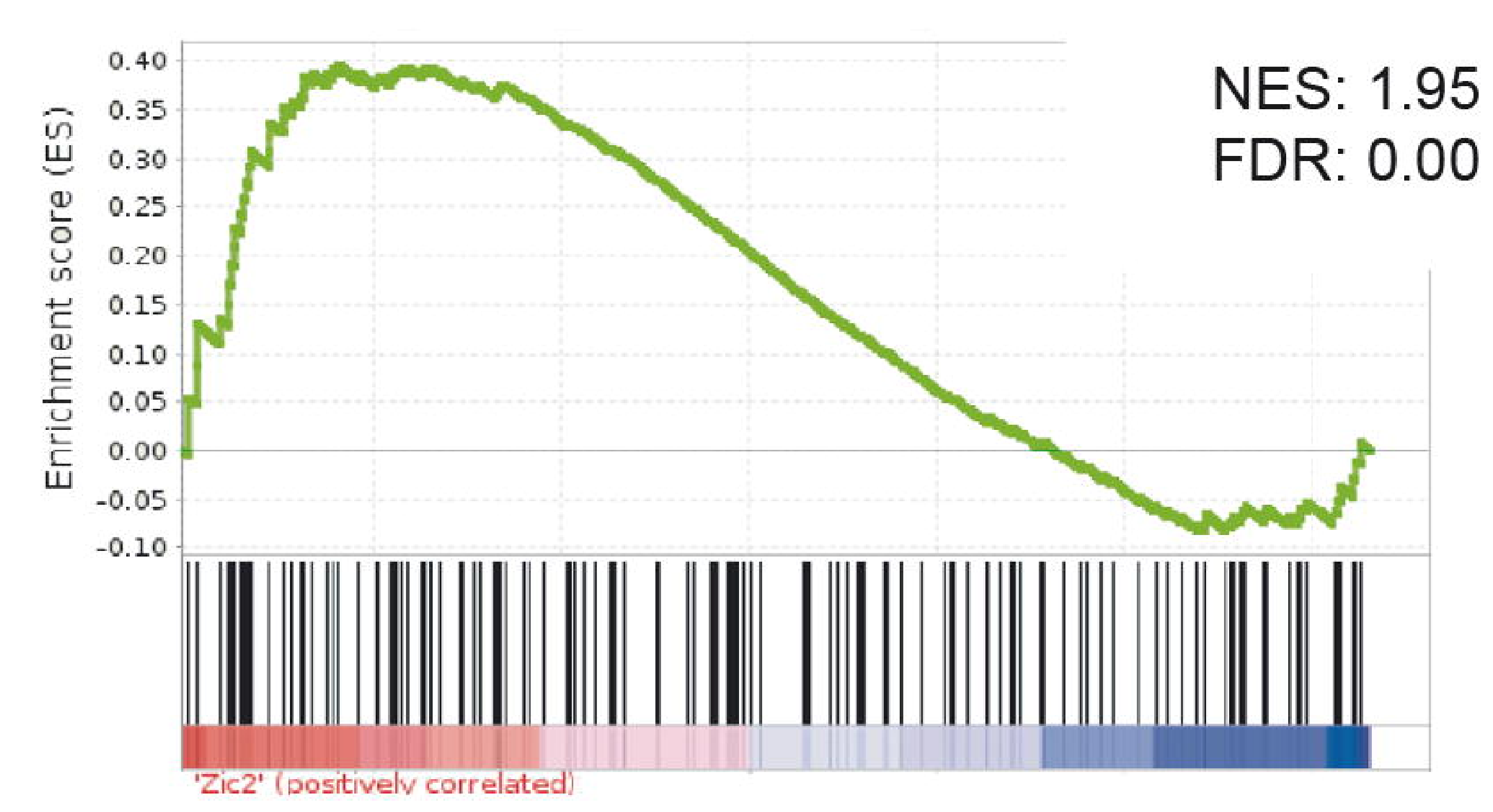


A

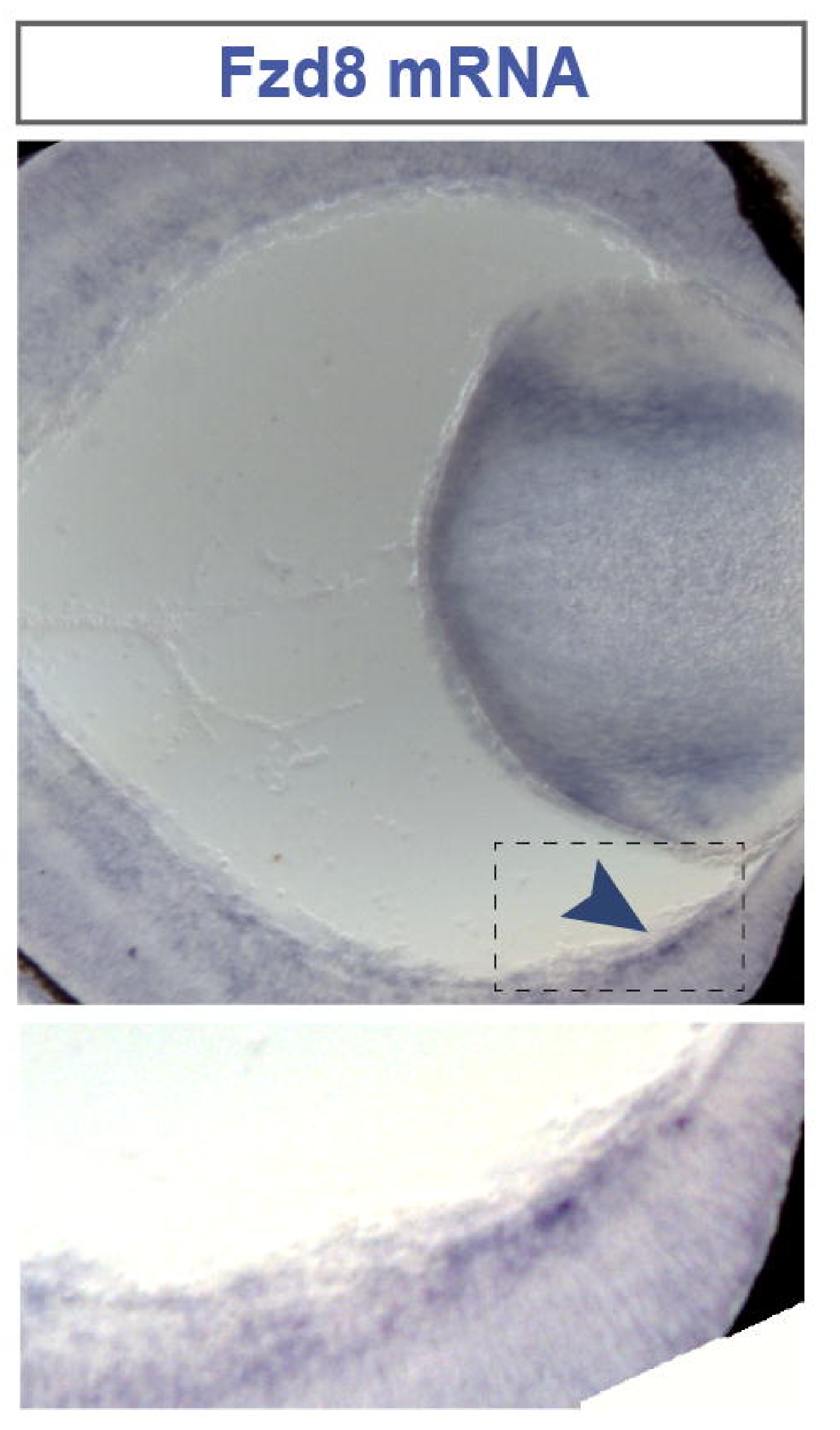

D



F

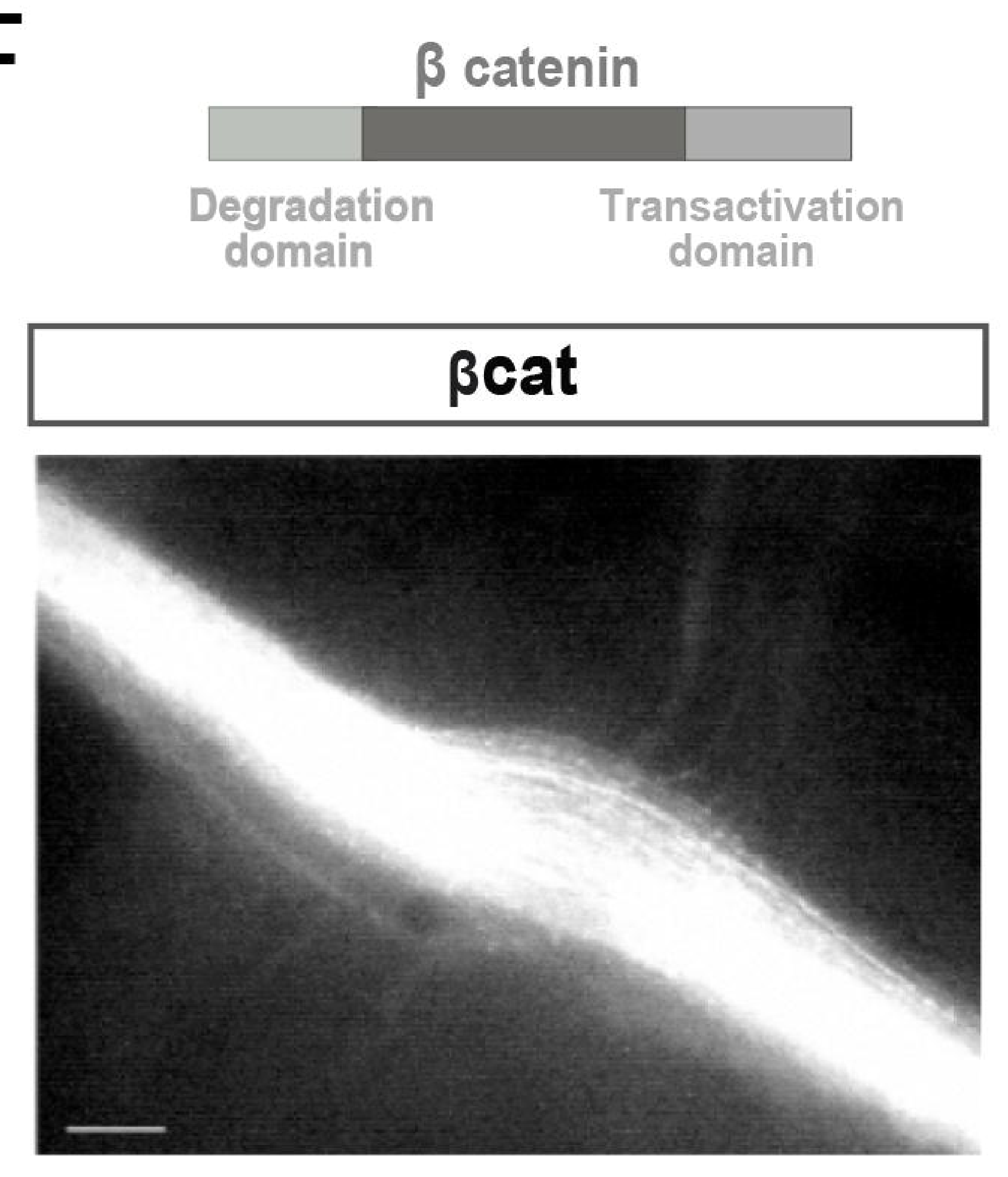

B
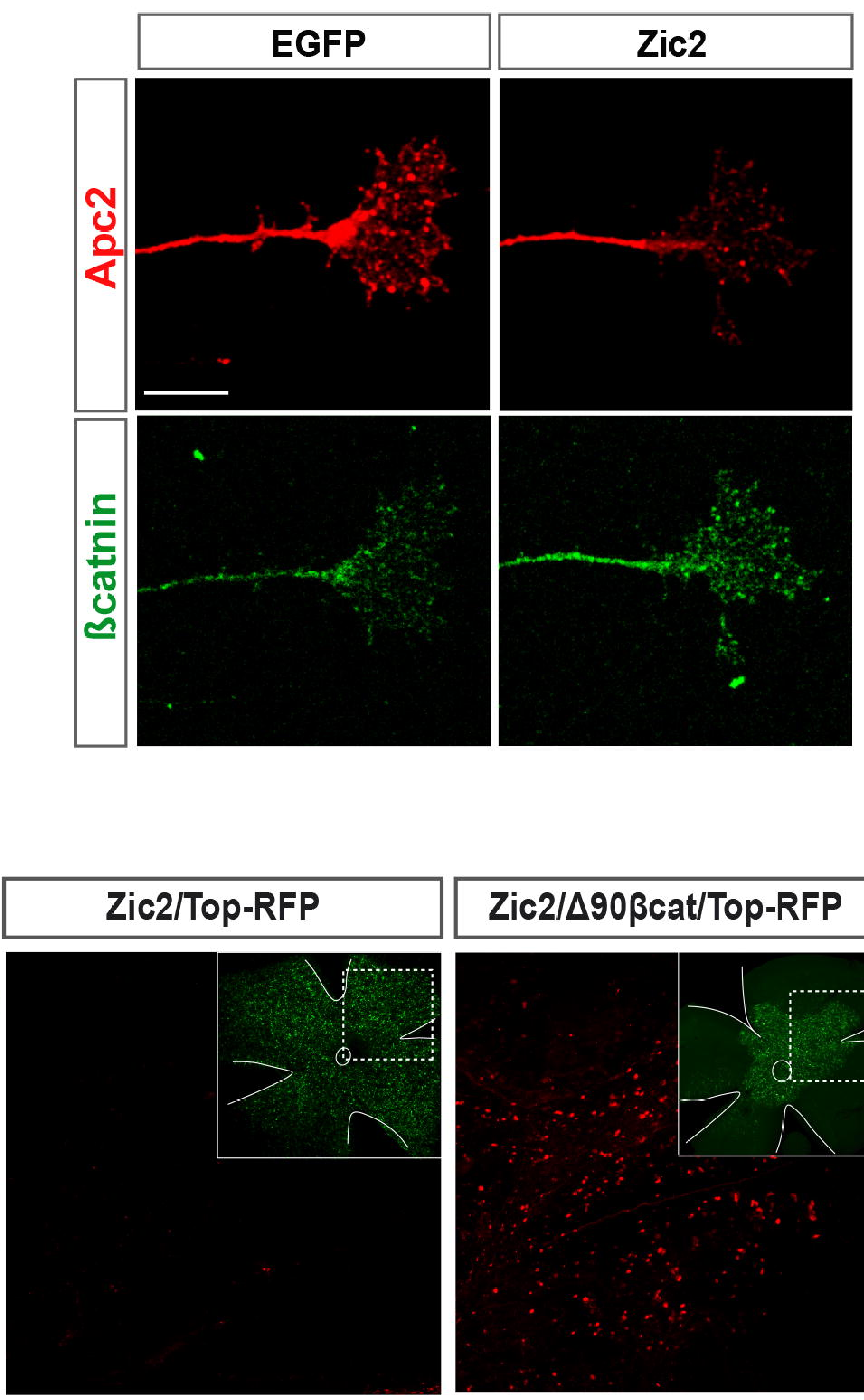

Zic2/ $\Delta 90 \beta c a t / T o p-R F P$

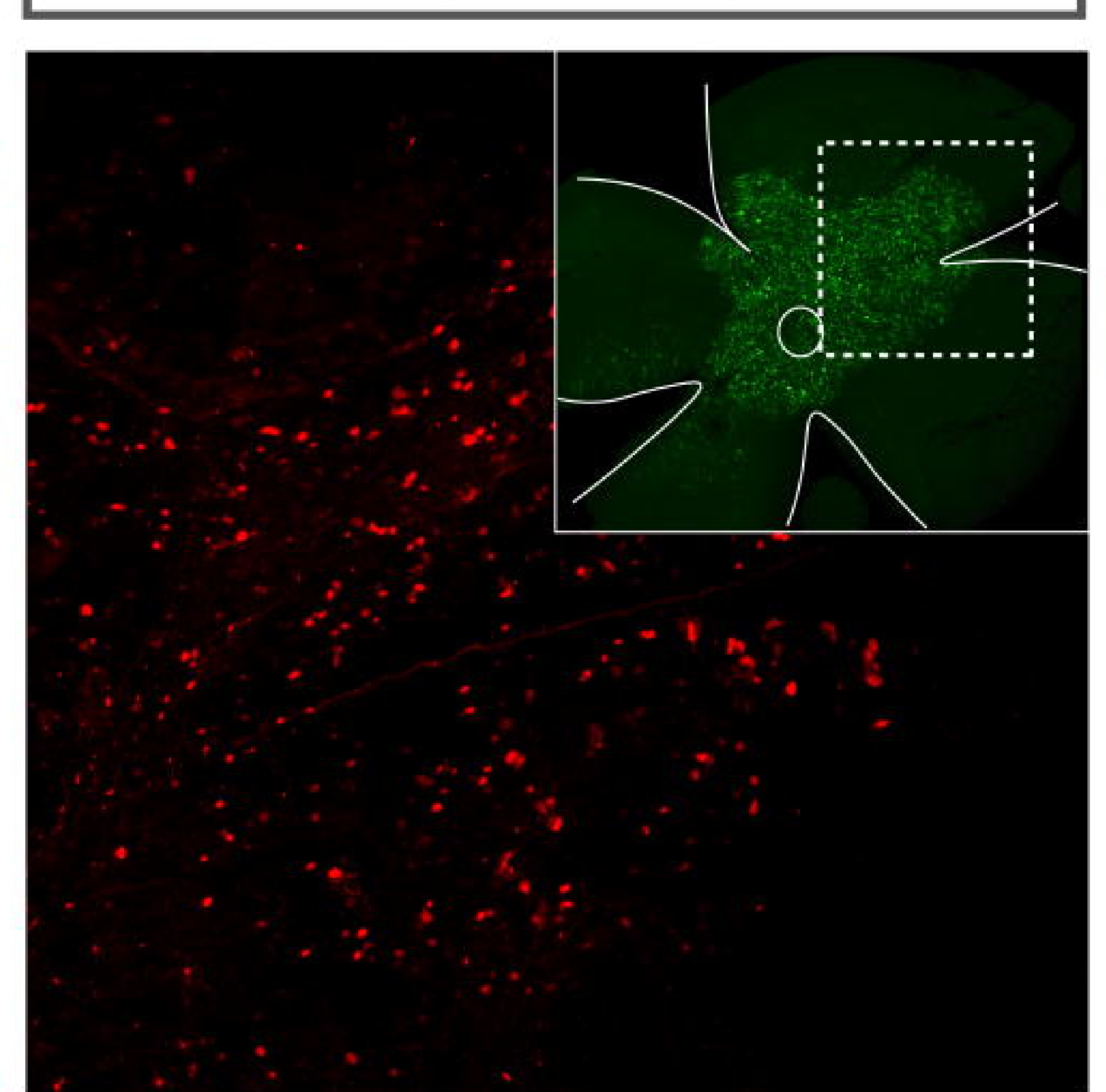

C

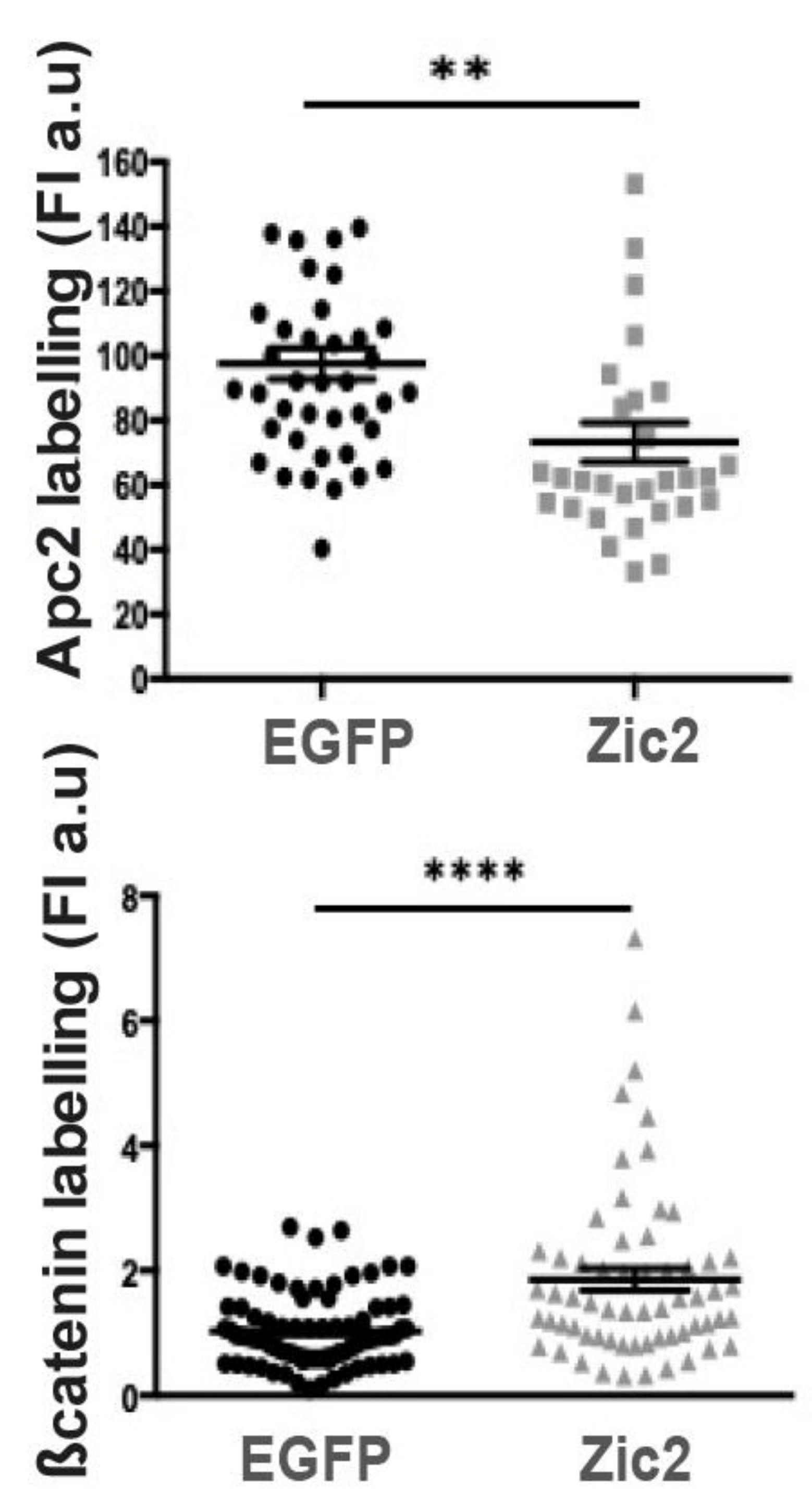

E

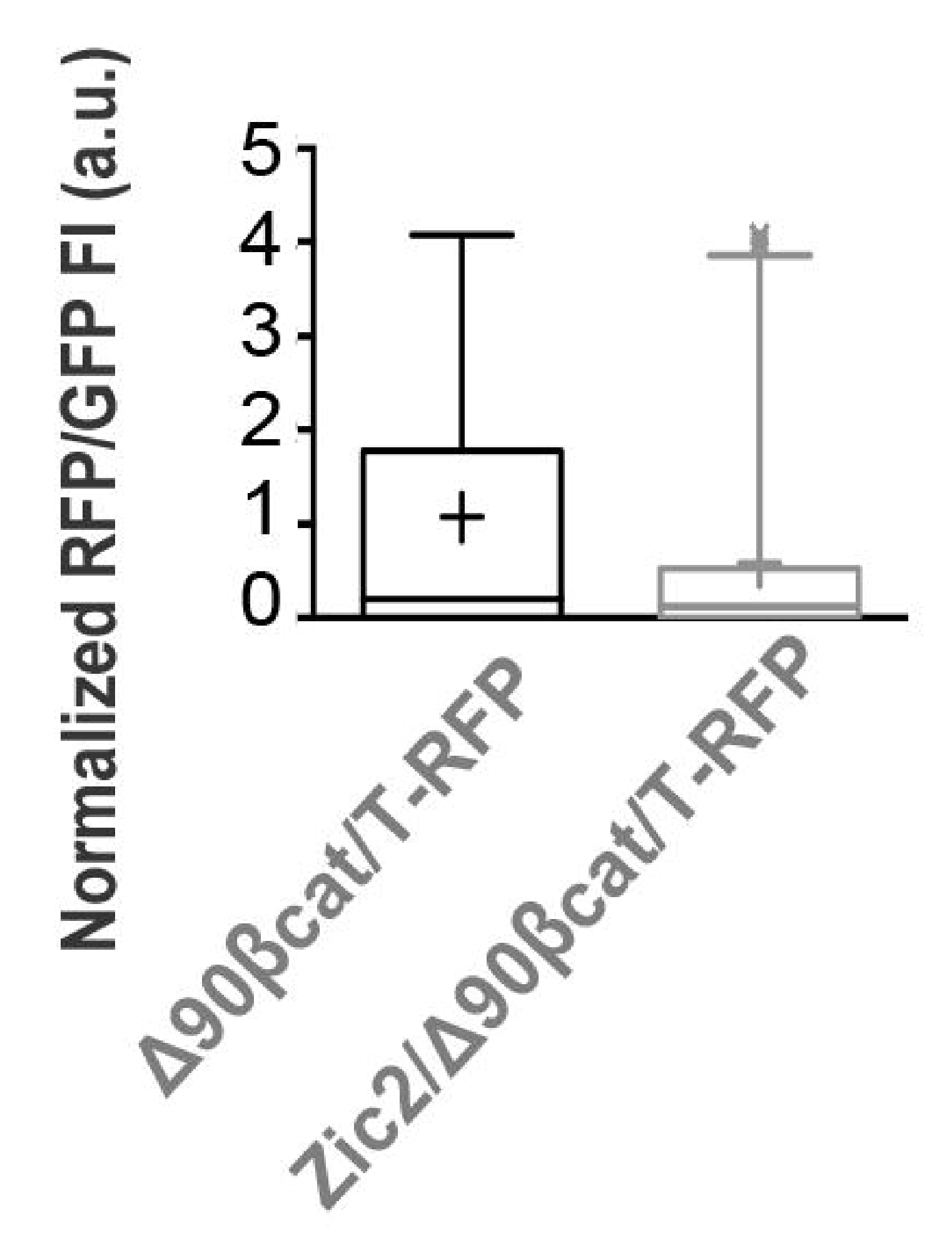

Figure 6

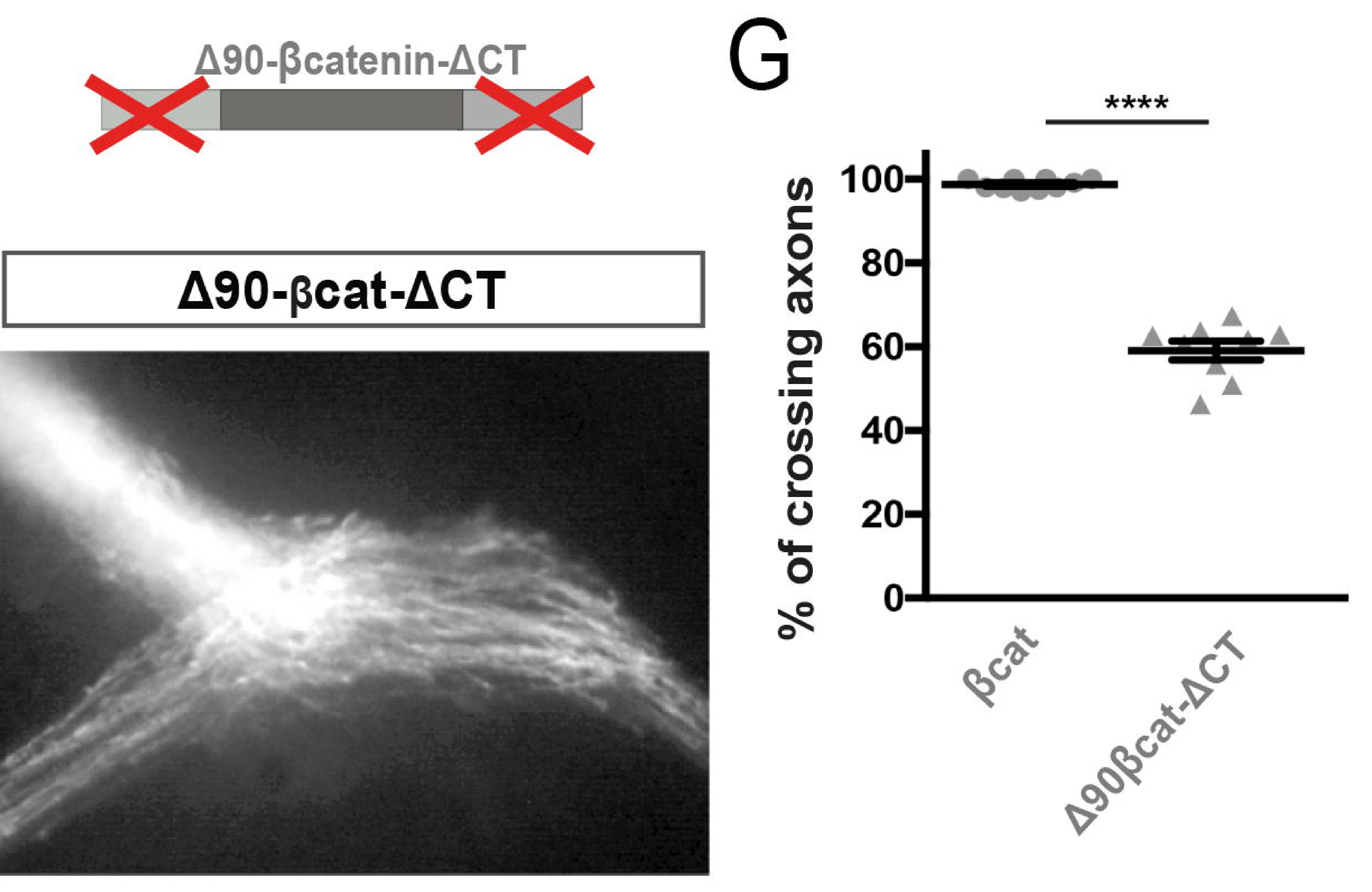



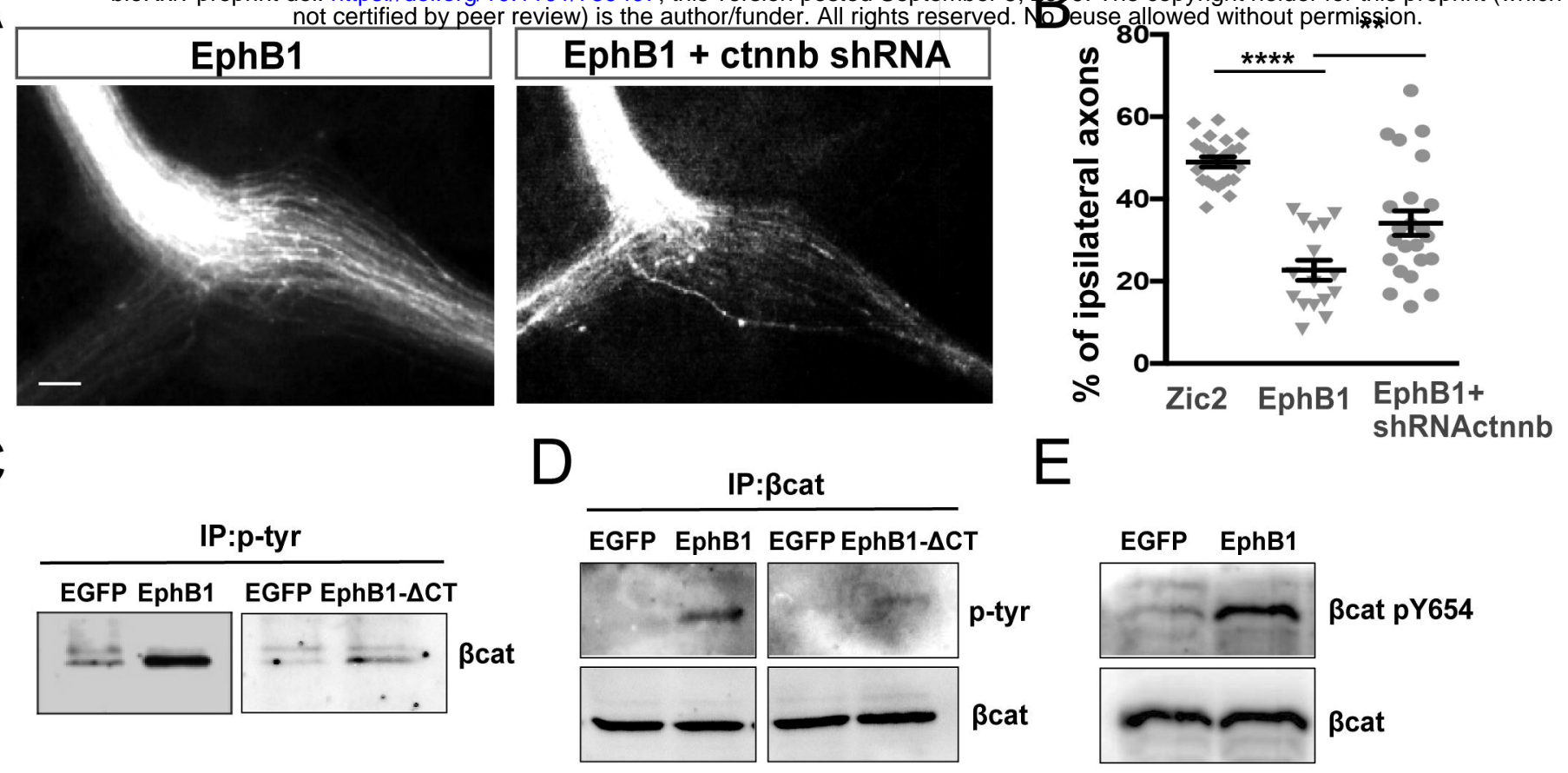

ßcat pY654

$\mathrm{F}$

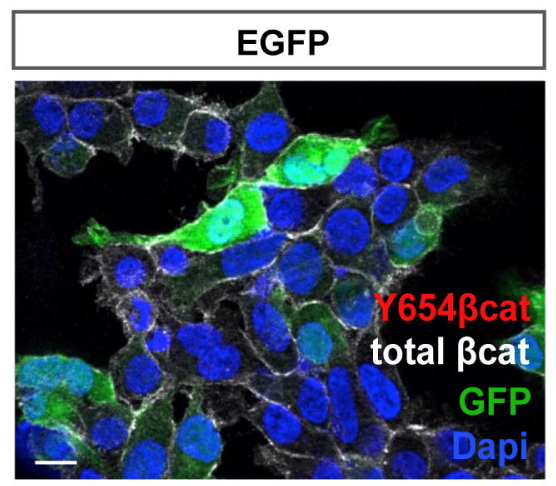

I

\section{Crossing axons}

Polarized accumulation of $\beta$ cat mediated by Wnt5a
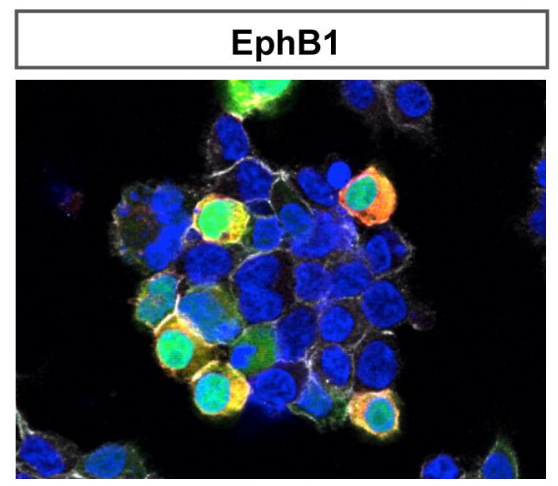

G
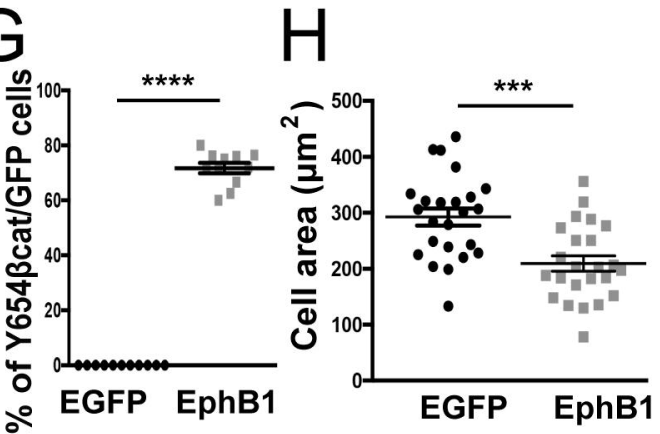

Wnt receptors

- $\beta$ catenin

- Y654ßcat

- Apc2

Cadherin

Wnt5a

\section{EphB1}

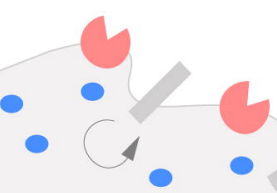

$\beta c a t$ 